\title{
THE INTERACTION BETWEEN ENVIRONMENTAL CONDITIONS AND GENETIC EXPRESSION OF RECENT DEVELOPED LOCAL F1 CANTALOUPE HYBRIDS (CUCUMIS MELO VAR. CANTALOUPENSIS)
}

\author{
M.A.M. Selim(1) and Fatma S.S. Alian(2) \\ (1) Vegetable Breeding Res. Dept. Hort. Inst. Agric. Res. Cent. Giza, Egypt. \\ (2) Potato and vegetatively propagated vegetable Res. Dept. Hort. Inst. Agric. Res. Cent. \\ Giza, Egypt
}

Received: Sep. 5, 2018

Accepted: Sep. 27, 2018

\begin{abstract}
The effect of six planting dates i.e., 15/1, 15/3, 15/5, 15/7, 15/9 and 15/11 on growth, yield and fruit quality of five newly developed local cantaloupe hybrids, Yathreb 7, 8, 22, 4 and 100 (Cucumis melo var. cantaloupensis) was studied under Sadat city, Menofia Governorate, Egypt conditions for two years, using split-plot design and the combined analysis was conducted for the two years. This experiment was carried out in the open field using a drip-irrigation system to determine the best planting date for each hybrid. Data were recorded on leaf area index (LAI), flowering, yield components, fruit quality and chemical determinations. Results showed that there were significant differences among planting dates in all studied traits. Also, cantaloupe hybrids had significant differences in all studied traits. Hybrid Yathreb 22 was the earliest one but it ranked as the second in total and marketable yield. Additionally, hybrid Yathreb 7 had the highest total and marketable yield, meanwhile Yathreb 100 ranked as the second in total yield but first in marketable yield. These hybrids had high values of the most other traits. The interaction between planting date and hybrid indicated that the best planting date for Yathreb 7 and 8 was 15/1 and 15/3, Yathreb 22 was 15/1 and 15/11, Yathreb 100 was 15/3, 15/5 and 15/7 and Yathreb 4 was 15/3 only. Each of them gave the best performance in the most of studied traits in the previous planting dates. While the planting date 15/9 wasn't suitable for cantaloupe growing at lower Egypt and this due to the cantaloupe sudden wilt which may be occur as result to low night temperatures. The present study confirmed that the interaction between planting date and hybrid effects on the performance of the hybrid either positive or negative impacts according to the interaction between genotype and environmental conditions.
\end{abstract}

Key words: Cucumis melo var. cantaloupensis, Cantaloupe, Hybrids, Planting dates, Leaf area index, Flowering,Yield components, Fruit quality, Chemical determinations.

\section{INTRODUCTION}

The melon crop (Cucumis melo L.) is very sensitive to air temperature, not tolerating frosts at any stage of its growth. The higher average temperature causes an increased rate of crop development and is responsible for earlier fruit maturation (Pardossi et al., 2000). The importance of studies that relate this environmental factor with the development of the plant stands out previously by other authors (Jenni et al., 1996; Amuyunzu et al., 1997; Ventura and Mendlinger, 1999 and Baker and Reddy, 2001). In general, the temperature has the strongest impact on all plant growth stages as compared with other environmental factors. So, the knowledge of the effect of temperature on the crop is of great importance for crop growth models (Hakojärvi et al., 2010). 
Also, netted muskmelon (Cucumis melo L., reticulatus group), commonly called cantaloupe is an green-fleshed, sweet and aromatic melon that is highly popular in Egypt, representing a large share in the production market (Hussein and Selim, 2014).

The temperature is one of the major factors affecting plant growth, flowering, fruiting and crop quality of melon crop. High temperatures cause increased to the rate of respiration compared to the rate of photosynthesis. This means that the products of photosynthesis are being exhausted more rapidly than they are being produced. For growth vigor, the photosynthesis rate must be greater than the respiration rate (Refai et al., 2008).

Changes in melon quality are the result of complex genetic, physiological and environmental influences. So, the interaction between genotype and environmental factors has a great effect on the melon quality (Beaulieu and Grimm, 2001; Beaulieu et al., 2004; Beaulieu and Lancaster, 2007; Pratt, 1971). From the consumer's standpoint, quality melons must be sweet, flavorful, and reasonably firm. Various studies have been published in diverse locations evaluating the performance of various melons planted on multiple planting dates in Korea (Lee et al., 1998), Jamaica (McGlashan and Fielding, 1990), Texas (Bruton et al., 1985), and India (Nandpuri and Lai, 1978). The conclusions reached are specific to those regions because of genotype/environment interactions that modify plant growth to unique climatic conditions. Amuyunzu et al. (1997) found that variation among the cultigens both between and within temperature regimes was significant for most of vegetative growth. Also, Baker and Reddy (2001), growing on six planting dates (from March to June) found that main vine plastochron interval was significantly affected by both cultivar and transplanting date. Final yield of muskmelon was sharply reduced in the last two planting dates, presumably due to high temperature stress impairing reproductive development.

Russo et al. (2002) found that various members of the cucurbit crops exhibit differences in plant development and these may be affected by environmental factors. Plants from the June planting had a longer primary runner, more leaves with a greater leaf area and dry weight, and higher above ground vegetative and total plant dry weights. Leaf area, leaf dry weight, total above ground vegetative and total plant dry weight was still increasing at harvest of the first fruit. The data describe a model for melon development. However, it is expected that changes in cultivars, cultural methods or environmental conditions can affect development and in turn the size and quality of fruit.

Dufault et al. (2006) conducted a study to determine if early (February) transplanted melons or later (June through July) planting dates are effective in extending the production season of acceptable yields with good internal quality of the melon cultivars Athena, Eclipse, Sugar Bowl and Tesoro Dulce (a honeydew melon). Comparing the marketable number of melons produced per plot (averaged over cultivar) of the standard planting dates of 12 and 26 March indicated decreases of $21 \%, 32 \%$, $36 \%, 36 \%, 57 \%, 57 \%$ and $54 \%$, respectively with the planting dates of 9 and 23 April, 7 and 21 May, 4 and 18 June and 2 July. The earliest recommended planting date with acceptable yield and good internal quality was March 12th for all cultivars. The optimal yield of cantaloupe is dependent on cultivar, crop management system, and growing season (Jensen and Malter, 1995; Lorenzo and Castilla, 1995). 
The objective of this study was to detect the suitable planting date to obtain high yield and quality of five local cantaloupe hybrids produced by the first author under Egyptian conditions and extending the production season of these hybrids.

\section{MATERIALS AND METHODS}

This study was carried out at Private farm, Sadat city, Menofia Governorate during six planting dates ( $15^{\text {th }}$ of March, May, July, September, November and January ) of 2016, 2017 and 2018 in the open field using a drip-irrigation system and polyethylene plastic mulch. Five local melon hybrids (Cucumis melo var. cantaloupensis), viz., Yathreb 7, 8, 22, 4 and $\mathbf{1 0 0}$ were used in this investigation. These hybrids were developed and introduced by the first author of the present study.

The treatments were arranged in split plot design with 3 replicates. Each experimental plot (EP) consisted of 1 bed, $1.5 \mathrm{~m}$ wide and $10 \mathrm{~m}$ long $(E P=15$ $\mathrm{m}^{2}$ ). Each replicate consisted of 6 planting dates as main plot, while 5 local cantaloupe hybrids as sub-plot factor.

Seeds of these local cantaloupe hybrids were sown before each planting date with 21 days during 2016, 2017 and 2018 in foam trays under greenhouse and transplanted on $15^{\text {th }}$ of March, May, July, September, November and January during 2016, 2017 and 2018 in the open field. The seedlings of each hybrid were transplanted at $50 \mathrm{~cm}$ apart along the drip-irrigation tube of each replicate. Also, Plants were given common agricultural practices.

The measured traits were:

1. Leaf area index ( LAI ): The leaf area of each plant was determined after maturity of fruits by the area meter (LICOR, model: LI 3050A/4,U.S.A) measured as an average of 3 randomly chosen plants per EP and the LAI was calculated by average leaf area, then dividing by the ground area occupied by the plant.

2. Flowering: Three plants were randomly chosen per EP to determine the number of days from transplanting to appearance of the first andromonocious flower on the plant.

3. Yield: Early yield (EY) was measured as the yield of the first 3 pickings, total yield (TY) was measured as the weight of all fruits harvested at the yellow-netted ripe stage from each EP. Marketable yield (MY) was determined after excluding cracked, rotten and infected fruits with diseases and pests.

4. Fruit quality: average fruit weight (AFW), seed cavity diameter and flesh thickness were determined as the mean of 15 fruits randomly chosen from each EP, fruit shape index (FSI) calculated as the ratio of fruit length to fruit diameter. Each EP was represented by 15 fruits. Fruits with a FSI less than 0.88 were classified as oblate, those with a FSI ranging from 0.88 to 1.1 were considered round, those with a FSI ranging from 1.1 to 1.5 were classified as cylindrical and those with a FSI above 1.5 were classified as oblong (Rashidi and Seyfi, 2007). The netting percentage was measured as a ratio of the netting covered fruit rind to full fruit rind as visual method and determined as the mean of 15 fruits randomly chosen from each EP. Total soluble solids (TSS) was determined in 15 yellowripe fruits of each EP using a hand refractometer.

5. Chemical determinations : 100 gram fresh leaves and fruit flesh from each EP were dried in the oven at $65^{\circ} \mathrm{C}$ for 48 and 72 hours, respectively, then the dry matter was weighted by sensitive 
balance to determine the leaves (LDM) and flesh dry matter (FDM) percentage as a ratio of dry matter weight to total fresh weight. Also, 0.1 gram ground FDM for each EP was used to estimate the total sugars and reduced sugars using spectrophotometer with wave length $490 \mathrm{~nm}$ according to Dubois et al. (1956).

\section{Statistical Analysis:}

Obtained data were statistically analyzed and mean comparisons were based on the LSD test according to Gomez and Gomez (1984). Also, the Bartlett's test (using Chi-square test) of the two variance of errors for both years (from 2016 to 2018) were homogeneous for all traits. So, the combined analysis of variance for the two years was computed for all traits according to Koch and Sen (1968).

\section{Recorded Temperatures:}

Temperature was recorded during the six planting dates of 2016, 2017 and 2018 in the open field. Field temperature was measured using a Micro Data Logger,
Operon Company, UK. Temperature was recorded every hour throughout the growing season. The lowest and the highest temperature per month, mean monthly minimum and maximum temperatures and the mean monthly temperature of 2016, 2017 and 2018 are presented in Table 1 and Figures 1, 2 and 3.

\section{RESULTS AND DISCUSSION}

\section{Leaf Area Index}

Obtained data of combined analysis on LAl during the period from 2016 to 2018 were combined in Table 2 and Fig. 4.

Data showed that the highest value of LAl was recorded in planting date 15/7, while the lowest value of LAl was recorded in planting date 15/9. They were significantly different over all other planting dates. With regard to genotypes, hybrid Yathreb 8 had the highest LAl, while Yathreb 4 had the least LAl. They had significant differences from all other evaluated hybrids.

Table 1. Monthly temperature during 2016, 2017 and 2018 at Sadat city, Menofia Governorate, Egypt.

\begin{tabular}{|c|c|c|c|c|c|c|c|c|c|c|c|c|c|c|c|}
\hline \multirow[t]{2}{*}{ Month } & \multicolumn{3}{|c|}{$\begin{array}{c}\text { Lowest } \\
\text { temperature } \\
\left({ }^{\circ} \mathrm{C}\right)\end{array}$} & \multicolumn{3}{|c|}{$\begin{array}{c}\text { Highest } \\
\text { temperature } \\
\left({ }^{\circ} \mathrm{C}\right)\end{array}$} & \multicolumn{3}{|c|}{$\begin{array}{l}\text { Mean monthly } \\
\text { minimum } \\
\left({ }^{\circ} \mathrm{C}\right)\end{array}$} & \multicolumn{3}{|c|}{$\begin{array}{l}\text { Mean monthly } \\
\text { maximum } \\
\left({ }^{\circ} \mathrm{C}\right)\end{array}$} & \multicolumn{3}{|c|}{$\begin{array}{l}\text { Mean monthly } \\
\left({ }^{\circ} \mathrm{C}\right)\end{array}$} \\
\hline & 2016 & 2017 & 2018 & 2016 & 017 & 2018 & 2016 & 2017 & 2018 & 2016 & 2017 & 2018 & 2016 & 2017 & 2018 \\
\hline Mar. & 6.5 & 7.5 & 4.5 & 27.0 & 28.5 & 25.8 & 10.6 & 12.5 & 13.4 & 25.5 & 26.9 & 24.0 & 17.5 & 19.5 & 18.8 \\
\hline Apr. & 8.0 & 5.5 & 7.0 & 30.0 & 29.5 & 28.0 & 12.4 & 13.0 & 15.5 & 27.8 & 28.7 & 26.0 & 20.0 & 21.4 & 20.7 \\
\hline May & 9.5 & 8.4 & 8.0 & 31.5 & 29.0 & 32.0 & 17.8 & 12.7 & 14.5 & 29.0 & 25.0 & 28.4 & 23.6 & 19.8 & 22.0 \\
\hline June & 10.4 & 8.5 & 9.0 & 35.8 & 38.5 & 35.0 & 20.6 & 19.8 & 21.4 & 31.6 & 30.5 & 29.8 & 28.5 & 27.0 & 26.4 \\
\hline July & 12.0 & 17.0 & --- & 40.8 & 39.0 & --- & 19.6 & 25.0 & --- & 33.5 & 35.9 & --- & 30.4 & 29.3 & --- \\
\hline Aug. & 15.5 & 25.5 & --- & 43.4 & 42.9 & --- & 27.4 & 32.3 & --- & 39.6 & 38.6 & --- & 32.6 & 31.9 & --- \\
\hline Sept. & 10.0 & 9.5 & --- & 32.0 & 35.0 & --- & 20.0 & 19.5 & --- & 28.8 & 31.5 & --- & 25.4 & 26.8 & --- \\
\hline Oct. & 8.0 & 7.0 & --- & 27.0 & 25.8 & --- & 17.8 & 20.0 & --- & 25.0 & 24.0 & --- & 19.6 & 20.0 & --- \\
\hline Nov. & 5.0 & 4.5 & --- & 25.8 & 22.5 & --- & 16.8 & 15.4 & --- & 23.6 & 20. & --- & 18.6 & 16.4 & --- \\
\hline Dec. & 3.0 & 4.0 & --- & 20.5 & 28.8 & --- & 15.2 & 13.4 & --- & 18.5 & 24.6 & --- & 16.3 & 17.0 & --- \\
\hline Jan. & 1.0 & 2.5 & --- & 22.5 & 27.0 & --- & 12.8 & 14.2 & --- & 20.0 & 19.9 & --- & 14.5 & 16.0 & --- \\
\hline Feb. & 1.5 & 1.0 & --- & 27.8 & 20.0 & --- & 9.8 & 11.9 & --- & 24.5 & 17.9 & --- & 13.0 & 14.8 & --- \\
\hline
\end{tabular}




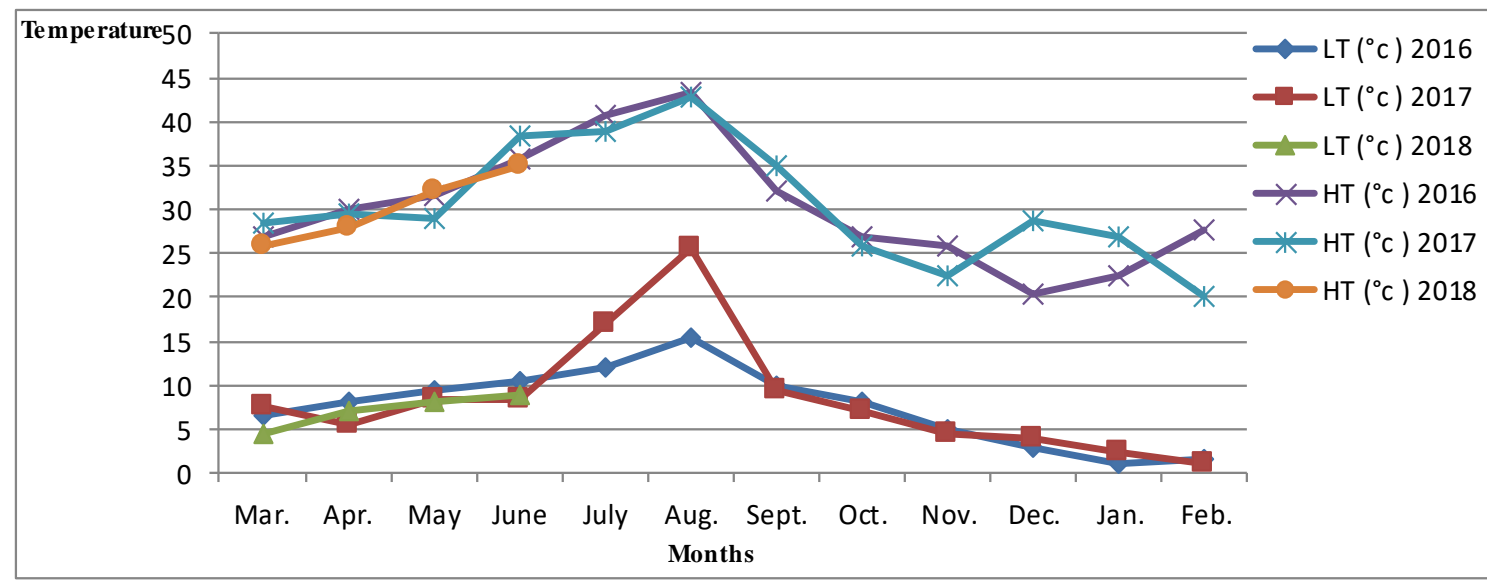

Fig. (1) The lowest (LT) and highest (HT) temperature during the period from 1/3/2016 to 30/6/2018.

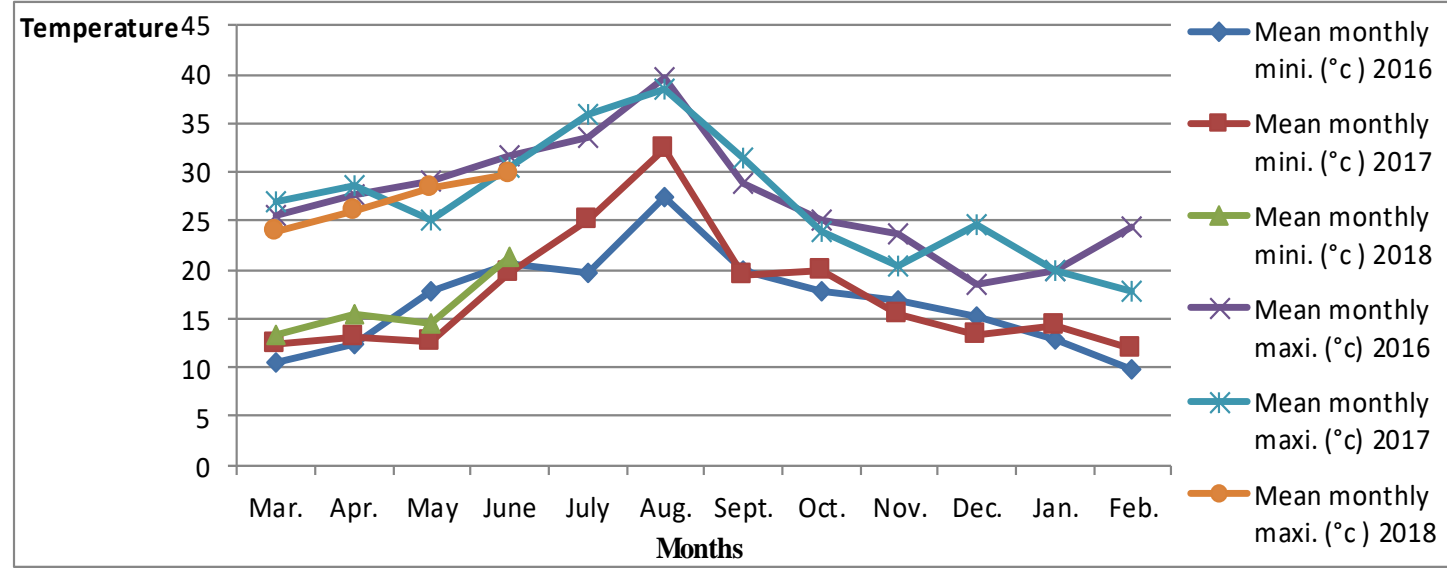

Fig. (2): The mean monthly minimum and maximum temperature during the period from $1 / 3 / 2016$ to $30 / 6 / 2018$.

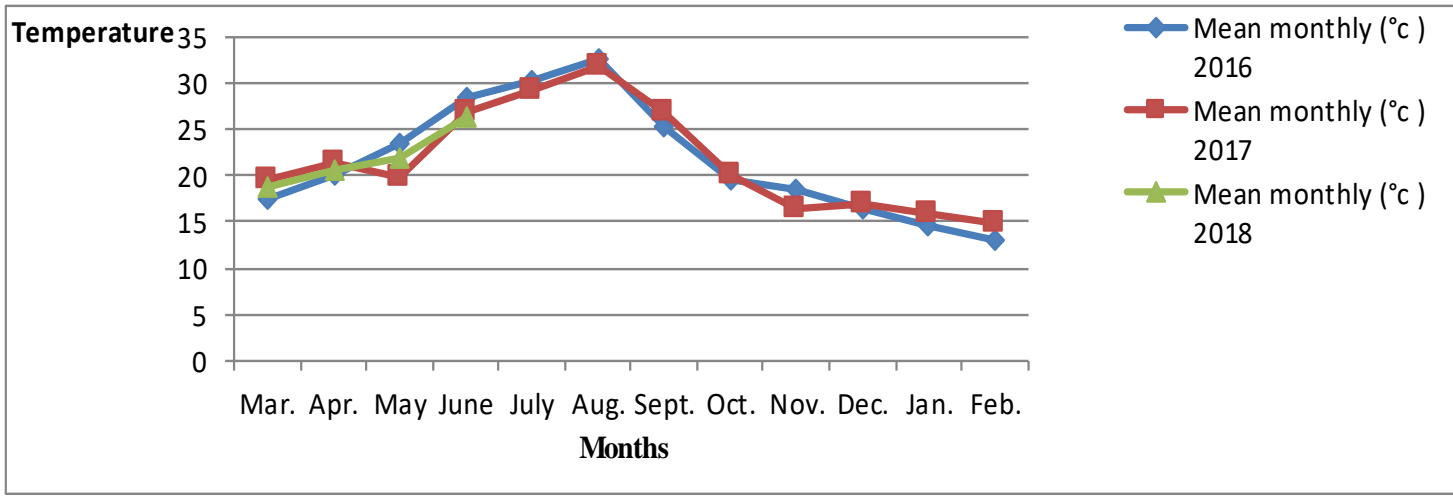

Fig. (3) The mean monthly temperature during the period from $1 / 3 / 2016$ to $30 / 6 / 2018$. 
Table 2. The effects of planting date, hybrid and the interaction among them on Leaf area index and flowering during the period from 2016 to 2018 in a combined analysis for two years of each planting date.

\begin{tabular}{|c|c|c|c|}
\hline \multirow{2}{*}{ Treatment } & \multicolumn{2}{|r|}{ LAI } & Flowering (day) \\
\hline & \multicolumn{3}{|c|}{ Planting date } \\
\hline $15 / 3$ & & $1.55 \mathrm{c}$ & $47.10 \mathrm{c}$ \\
\hline $15 / 5$ & & $1.64 \mathrm{~b}$ & $45.75 d$ \\
\hline $15 / 7$ & & $1.71 \mathrm{a}$ & $44.80 \mathrm{e}$ \\
\hline $15 / 9$ & & $1.39 \mathrm{e}$ & $48.25 \mathrm{~b}$ \\
\hline $15 / 11$ & & $1.47 \mathrm{~d}$ & $49.53 \mathrm{a}$ \\
\hline \multirow[t]{2}{*}{$15 / 1$} & & $1.65 \mathrm{~b}$ & $48.75 a b$ \\
\hline & \multicolumn{2}{|c|}{ Genotype } & \\
\hline Yathreb 7 & & 1.64 b & $45.52 d$ \\
\hline Yathreb 8 & & $1.89 \mathrm{a}$ & $52.23 \mathrm{a}$ \\
\hline Yathreb 22 & & $1.53 \mathrm{~d}$ & $43.58 \mathrm{e}$ \\
\hline Yathreb 4 & & $1.22 \mathrm{e}$ & $46.27 \mathrm{c}$ \\
\hline Yathreb 100 & & $1.57 \mathrm{c}$ & $49.21 \mathrm{~b}$ \\
\hline \multicolumn{4}{|c|}{ The interaction } \\
\hline Planting date & Hybrid & & \\
\hline \multirow[t]{5}{*}{$15 / 3$} & Yathreb 7 & 1.59 ef & $45.25 \mathrm{klmn}$ \\
\hline & Yathreb 8 & $1.93 \mathrm{a}$ & $53.75 a b$ \\
\hline & Yathreb 22 & $1.51 \mathrm{fgh}$ & 42.63 op \\
\hline & Yathreb 4 & $1.23 \mathrm{k}$ & $44.00 \mathrm{mno}$ \\
\hline & Yathreb 100 & $1.52 \mathrm{fgh}$ & $49.88 \mathrm{cde}$ \\
\hline \multirow[t]{5}{*}{$15 / 5$} & Yathreb 7 & $1.78 \mathrm{~b}$ & 43.13 op \\
\hline & Yathreb 8 & $1.96 \mathrm{a}$ & 49.38 cde \\
\hline & Yathreb 22 & 1.57 ef & $41.75 p$ \\
\hline & Yathreb 4 & $1.30 \mathrm{jk}$ & $46.00 \mathrm{ijkl}$ \\
\hline & Yathreb 100 & 1.60 def & 48.50 defg \\
\hline \multirow[t]{5}{*}{$15 / 7$} & Yathreb 7 & $1.77 \mathrm{~b}$ & 43.13 op \\
\hline & Yathreb 8 & $2.03 \mathrm{a}$ & 48.38 efgh \\
\hline & Yathreb 22 & 1.59 ef & $41.88 p$ \\
\hline & Yathreb 4 & $1.44 \mathrm{ghi}$ & 43.88 no \\
\hline & Yathreb 100 & $1.70 \mathrm{bcd}$ & 46.75 hijk \\
\hline \multirow[t]{5}{*}{$15 / 9$} & Yathreb 7 & 1.54 efg & $45.63 \mathrm{jkIm}$ \\
\hline & Yathreb 8 & $1.73 \mathrm{bc}$ & $53.13 \mathrm{~b}$ \\
\hline & Yathreb 22 & $1.25 \mathrm{k}$ & $44.88 \mathrm{Imn}$ \\
\hline & Yathreb 4 & $1.01 \mathrm{I}$ & $47.50 \mathrm{fghi}$ \\
\hline & Yathreb 100 & $1.42 \mathrm{hi}$ & $50.13 \mathrm{~cd}$ \\
\hline \multirow[t]{5}{*}{$15 / 11$} & Yathreb 7 & $1.54 \mathrm{efg}$ & $47.50 \mathrm{fghi}$ \\
\hline & Yathreb 8 & 1.72 bc & $55.00 \mathrm{a}$ \\
\hline & Yathreb 22 & 1.61 def & $45.13 \mathrm{klmn}$ \\
\hline & Yathreb 4 & $0.94 I$ & 49.00 def \\
\hline & Yathreb 100 & $1.54 \mathrm{efg}$ & $51.00 \mathrm{c}$ \\
\hline \multirow[t]{5}{*}{$15 / 1$} & Yathreb 7 & 1.61 def & 48.50 defg \\
\hline & Yathreb 8 & $1.99 \mathrm{a}$ & $53.75 \mathrm{ab}$ \\
\hline & Yathreb 22 & $1.64 \mathrm{cde}$ & $45.25 \mathrm{klmn}$ \\
\hline & Yathreb 4 & $1.40 \mathrm{ij}$ & $47.25 \mathrm{ghij}$ \\
\hline & Yathreb 100 & $1.64 \mathrm{cde}$ & $49.00 \mathrm{def}$ \\
\hline
\end{tabular}

* Mean within a column followed by different letters is significantly different at 0.05 level. 


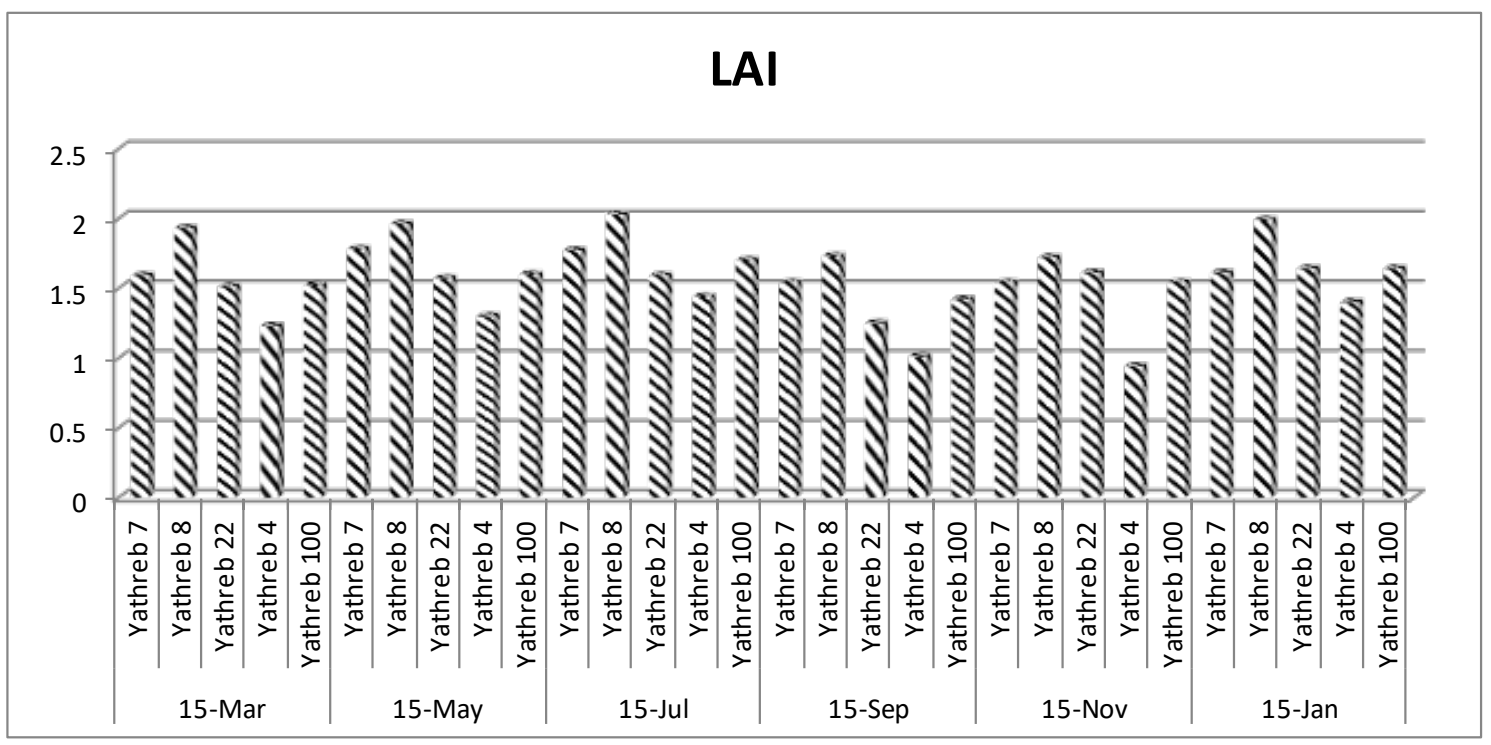

Fig. (4) The effects of the interaction between planting date and hybrid on leaf area index.

The interaction between planting date and hybrid indicated that Yathreb 8, which was grown in planting dates $15 / 3$, $15 / 5,15 / 7$ and 15/1, gave the highest LAI and was significantly different from all other treatments. Yathreb 7, which was grown in planting date $15 / 5$ and $15 / 7$, ranked the second in LAl without significant difference from Yathreb 8 which was grown in planting dates $15 / 9$ and $15 / 11$ and Yathreb 100 which was grown in planting date 15/7. On the contrary, Yathreb 4, which was grown in planting dates 15/9 and 15/11, had the least LAI and was significantly different from all other treatments. These results indicated that the hybrid response during planting date, which had high temperatures, gave the highest LAl and vice versa. These results are in agreement with Baker and Reddy (2001) and Russo et al. (2002) who reported that main vine plastochron interval and vegetative growth vigor especially LAI were significantly affected by both cultivar and transplanting date in cucurbit crops.

\section{Flowering}

Combined analysis of flowering during the period from 2016 to 2018 are shown in Table 2 and Fig. 5.

Data showed that the least number of days till appearance of the first perfect flower was in planting date 15/7 and was significantly different over all other planting dates. On the contrary, the highest number of days till appearance of the first perfect flower was in planting date 15/11, but it was not significantly different from planting date 15/1. With regard to genotypes, hybrid Yathreb 22 was significantly earlier in flowering than all other hybrids. In the meantime, hybrid Yathreb 8 was significantly the latest in flowering compared with the other tested hybrids.

Concerning to the interaction between planting date and hybrid indicated that Yathreb 22, which was grown in planting dates $15 / 5,15 / 7$ and $15 / 3$, was the earliest in flowering, but it wasn't significantly different from Yathreb 7, which was grown in planting dates $15 / 5,15 / 7$. On the contrary, the latest flowering was shown in Yathreb 8, which was grown in planting date 15/11, but it wasn't significantly different in planting dates 15/3 and 15/1. The interaction between 


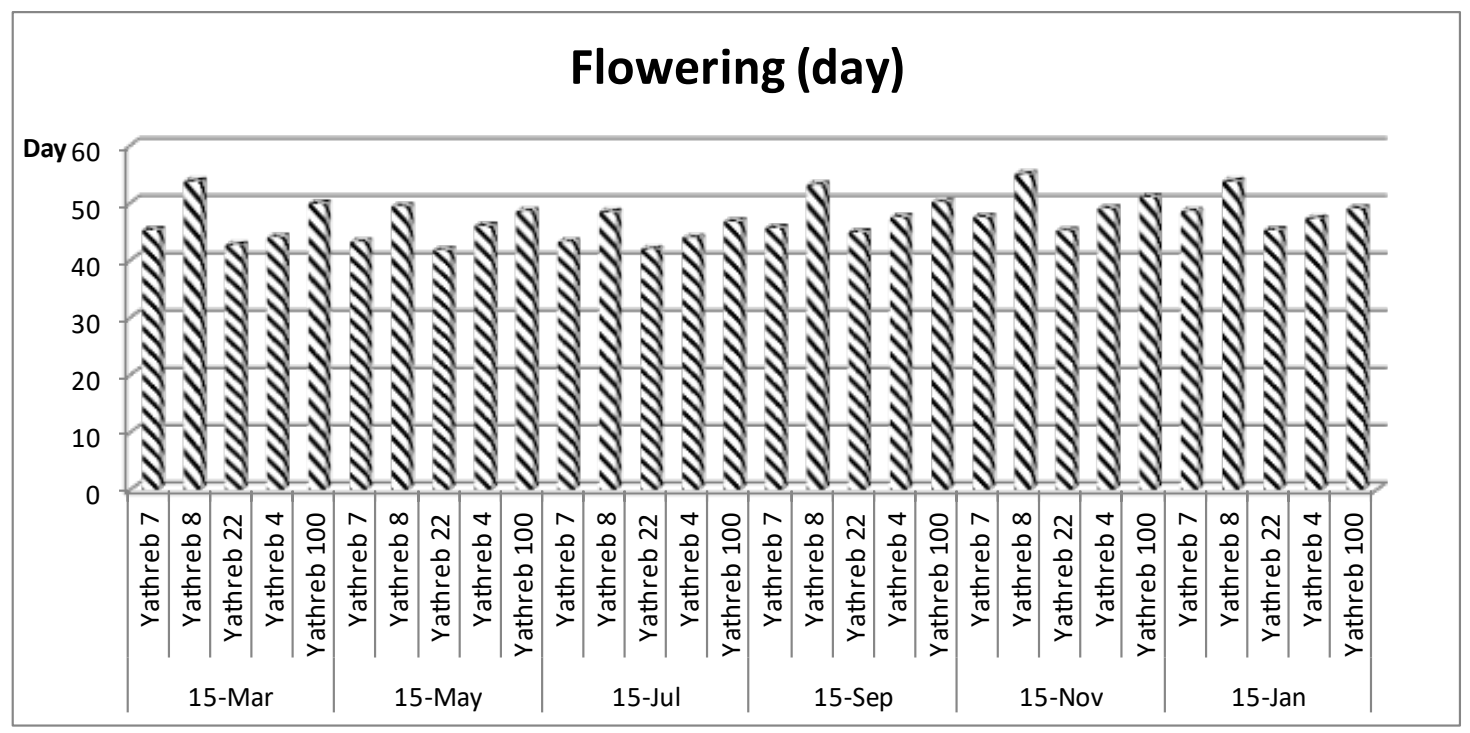

Fig. (5) The effects of the interaction between planting date and hybrid on flowering.

planting date and hybrid indicated that the planting dates, which had been high temperatures, caused early flowering for specific hybrids. So, the high temperatures had great impact on early flowering. These results are coincided with Refai et al. (2008) who reported that the temperature is one of the major factors affecting plant growth, flowering, fruiting and crop quality of melon crop. Also, Hakojärvi et al. (2010) stated that the temperature has the strongest impact on all plant growth stages as compared with other environmental factors. Furthermore, the knowledge of the effect of temperature on the crop had been a great importance for crop growth models.

\section{Yield and its Components}

Data of combined analysis on yield and its components during the experimental period are illustrated in Table 3 and Figures 6 and 7. The obtained data of yield and its components, fruit quality and chemical determinations were taken for only five planting dates because all plants were collapsed before fruit mature in planting date $15 / 9$ at the two years due to the melon sudden wilt which may be occur as result to low night temperatures. So, this planting date (15/9) wasn't suitable for cantaloupe growing at lower Egypt.
With regard to early yield, data indicated that the highest early yield was shown in planting date $15 / 5$, but it wasn't significantly different from 15/3, 15/7 and 15/1. The lowest early yield was shown in planting date 15/11, but it wasn't significantly different from 15/3, 15/7 and 15/1. Concerning to genotypes, Yathreb 22 had the highest early yield and was significantly different over all other hybrids. Also, Yathreb 7 ranked second in early yield and was significantly different over all other hybrids. In contrast, Yathreb 100 gave the lowest early yield, but it wasn't significantly different from Yathreb 4. Concerning to the interaction between planting date and hybrid indicated that Yathreb 22, which was grown in planting date 15/11, gave the highest early yield, but it wasn't significantly different in planting dates $15 / 3,15 / 5$ and from Yathreb 7, which was grown in planting date 15/1. On the other hand, Yathreb 8, which was grown in planting date 15/11, gave the lowest early yield, but it wasn't significantly different in planting dates 15/1, 15/3 and 15/7. These results are coincided with Refai et al. (2008) who reported that the interactions between planting dates and cantaloupe hybrids had great effect on 
early yield trait during the five planting dates. Moreover, they found that "Rafegal (c-8)" hybrid gave the highest values of early yield when planted in 15 of July in both years. While the lowest values were determined when "Galia" was planted in 15 of August.

Table 3. The effects of planting date, hybrid and the interaction among them on yield and its components during the period from 2016 to 2018 in a combined analysis for two years of each planting date.

\begin{tabular}{|c|c|c|c|c|}
\hline \multirow{2}{*}{ Treatment } & & $\begin{array}{c}\text { Early yield } \\
\text { (ton / feddan) }\end{array}$ & $\begin{array}{c}\text { Total yield } \\
\text { (ton / feddan) }\end{array}$ & $\begin{array}{c}\text { Marketable } \\
\text { yield(\%) }\end{array}$ \\
\hline & & \multicolumn{3}{|c|}{ Planting date } \\
\hline $15 / 3$ & & $1.46 \mathrm{ab}$ & $12.5 a b$ & 84.77 b \\
\hline $15 / 5$ & & $1.50 \mathrm{a}$ & $12.81 \mathrm{a}$ & $81.51 \mathrm{C}$ \\
\hline $15 / 7$ & & $1.41 \mathrm{ab}$ & $11.94 \mathrm{C}$ & 84.02 b \\
\hline $15 / 11$ & & $1.38 \mathrm{~b}$ & $11.41 \mathrm{~d}$ & $83.68 \quad b$ \\
\hline \multirow[t]{2}{*}{$15 / 1$} & & $1.46 \mathrm{ab}$ & $12.26 \mathrm{bc}$ & $86.67 \quad a$ \\
\hline & \multicolumn{4}{|c|}{ Genotype } \\
\hline Yathreb 7 & & $2.01 \mathrm{~b}$ & $13.18 \quad \mathrm{a}$ & 86.17 a \\
\hline Yathreb 8 & & $0.58 \mathrm{~d}$ & $11.83 \mathrm{C}$ & 86.42 a \\
\hline Yathreb 22 & & $2.27 \mathrm{a}$ & $12.39 \mathrm{~b}$ & 82.11 b \\
\hline Yathreb 4 & & $1.21 \mathrm{C}$ & $10.8 \mathrm{~d}$ & $79.94 \quad C$ \\
\hline \multirow[t]{2}{*}{ Yathreb 100} & & $1.14 \mathrm{c}$ & $12.72 \mathrm{~b}$ & 86.01 a \\
\hline & \multicolumn{4}{|c|}{ The interaction } \\
\hline Planting date & Hybrid & & & \\
\hline \multirow[t]{5}{*}{$15 / 3$} & Yathreb 7 & $2.01 \mathrm{~d}$ & $14.16 \mathrm{ab}$ & $87.35 \mathrm{abcd}$ \\
\hline & Yathreb 8 & $0.63 \mathrm{ij}$ & 12.94 def & $89.69 a b c$ \\
\hline & Yathreb 22 & $2.33 a b$ & 12.27 efgh & 78.46 jkl \\
\hline & Yathreb 4 & $1.27 \mathrm{fgh}$ & $10.87 \mathrm{ij}$ & $78.91 \mathrm{ijkl}$ \\
\hline & Yathreb 100 & $1.05 \mathrm{~h}$ & 12.25 efgh & $89.44 a b c$ \\
\hline \multirow[t]{5}{*}{$15 / 5$} & Yathreb 7 & $2.03 \mathrm{~d}$ & $14.96 \mathrm{a}$ & 82.54 fghij \\
\hline & Yathreb 8 & $0.70 \mathrm{i}$ & $13.97 \mathrm{bc}$ & 86.29 cdef \\
\hline & Yathreb 22 & $2.28 \mathrm{abc}$ & $12.00 \mathrm{fgh}$ & $76.94 \mathrm{kl}$ \\
\hline & Yathreb 4 & $1.34 \mathrm{f}$ & $10.56 \mathrm{j}$ & $75.27 I$ \\
\hline & Yathreb 100 & $1.15 \mathrm{fgh}$ & $12.58 \mathrm{efg}$ & 86.54 cdef \\
\hline \multirow[t]{5}{*}{$15 / 7$} & Yathreb 7 & $2.09 \mathrm{~cd}$ & 12.45 efgh & $88.08 \mathrm{abcd}$ \\
\hline & Yathreb 8 & $0.53 \mathrm{ij}$ & $10.4 \mathrm{j}$ & 86.82 bcde \\
\hline & Yathreb 22 & $2.18 \mathrm{bcd}$ & $10.87 \mathrm{ij}$ & 83.86 defgh \\
\hline & Yathreb 4 & $1.12 \mathrm{fgh}$ & 12.16 efgh & $78.51 \mathrm{jkl}$ \\
\hline & Yathreb 100 & $1.13 \mathrm{fgh}$ & $13.80 \mathrm{bcd}$ & 82.84 efghi \\
\hline \multirow[t]{5}{*}{$15 / 11$} & Yathreb 7 & $1.61 \mathrm{e}$ & $9.96 \mathrm{j}$ & 81.69 ghij \\
\hline & Yathreb 8 & $0.42 \mathrm{j}$ & $10.22 \mathrm{j}$ & 85.06 defg \\
\hline & Yathreb 22 & $2.45 \mathrm{a}$ & $14.74 \mathrm{ab}$ & $90.87 \mathrm{ab}$ \\
\hline & Yathreb 4 & $1.12 \mathrm{fgh}$ & $10.27 \mathrm{j}$ & $79.09 \mathrm{ijkl}$ \\
\hline & Yathreb 100 & $1.29 \mathrm{fg}$ & $11.88 \mathrm{gh}$ & $81.69 \mathrm{ghij}$ \\
\hline \multirow[t]{5}{*}{$15 / 1$} & Yathreb 7 & $2.30 \mathrm{abc}$ & $14.38 a b$ & $91.17 \mathrm{a}$ \\
\hline & Yathreb 8 & $0.62 \mathrm{ij}$ & $11.61 \mathrm{hi}$ & 84.26 defgh \\
\hline & Yathreb 22 & $2.08 \mathrm{~cd}$ & $12.07 \mathrm{fgh}$ & 80.43 hijk \\
\hline & Yathreb 4 & $1.22 \mathrm{fgh}$ & $10.16 \mathrm{j}$ & $87.95 \mathrm{abcd}$ \\
\hline & Yathreb 100 & $1.07 \mathrm{gh}$ & $13.11 \mathrm{cde}$ & $89.54 a b c$ \\
\hline
\end{tabular}

* Mean within a column followed by different letters is significantly different at 0.05 level. 


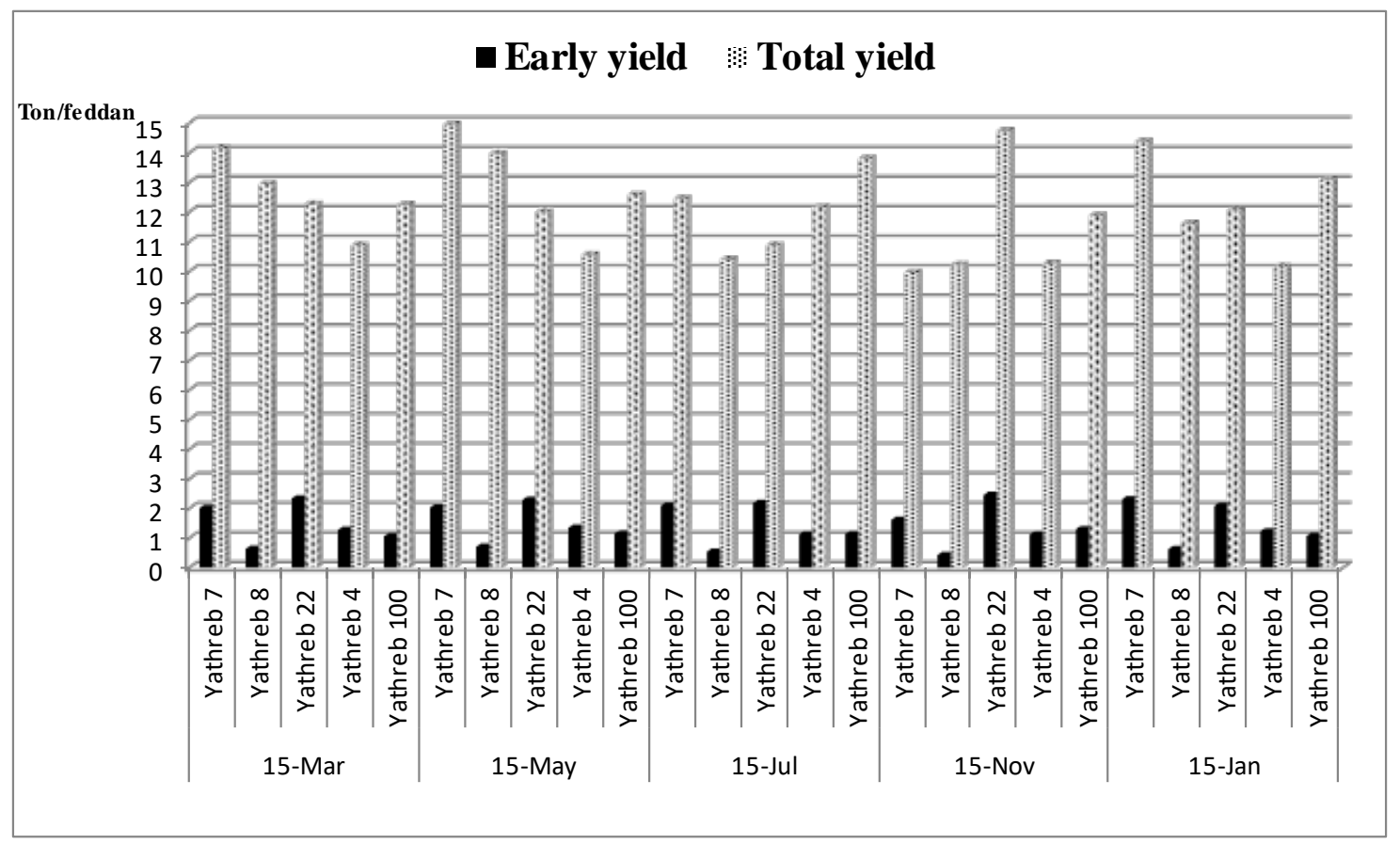

Fig. (6): The effects of the interaction between planting date and hybrid on early and total yield.

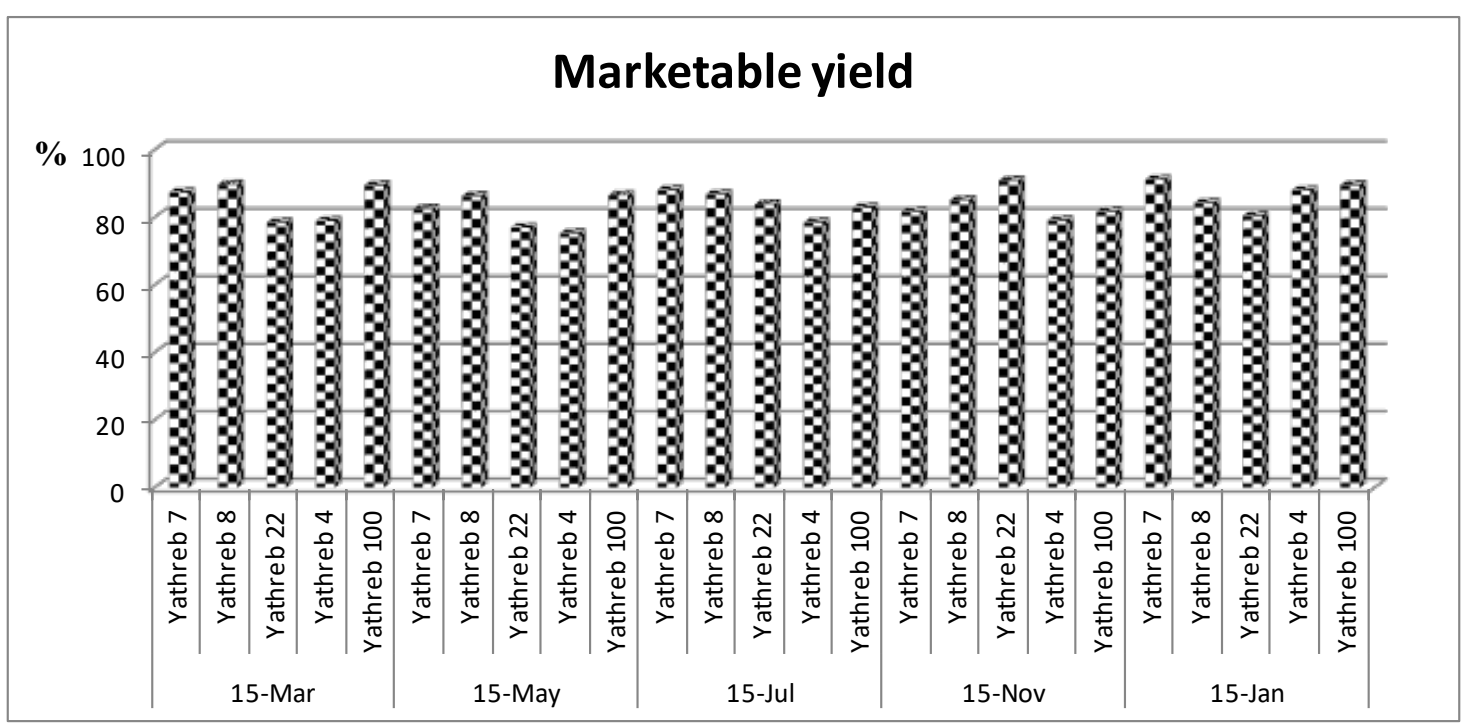

Fig. (7): The effects of the interaction between planting date and hybrid on marketable yield.

Concerning to total yield, the highest total yield was given in planting date $15 / 5$, but it wasn't significantly different from planting date 15/3. On the other hand, the lowest total yield was shown in planting date 15/11 and was significantly different over all other hybrids. With respect to genotypes, Yathreb 7 had the highest total yield and was significantly different over all other hybrids. Also, Yathreb 100 ranked second in total yield, but it wasn't significantly different from Yathreb 22. In contrast, Yathreb 4 gave the lowest total yield, and was significantly different over all other hybrids. Referring to the interaction 
between planting date and hybrid indicated that Yathreb 7 , which was grown in planting date $15 / 5$, gave the highest total yield, but it wasn't significantly different in planting dates $15 / 1,15 / 3$ and from Yathreb 22, which was grown in planting date 15/11. On the contrary, Yathreb 4, which was grown in planting date 15/1, gave the lowest total yield, but it wasn't significantly different in planting dates 15/3,15/5,15/11, and from Yathreb 8, which was grown in planting date 15/7 and 15/11, and Yathreb 22 and 7 which were grown in planting date $15 / 7$ and 15/11, respectively. These results are in agreement with those of Baker and Reddy (2001) who reported that the final yield of muskmelon was sharply reduced as a result of the interaction between cultivar and transplanting date. Also, the optimal yield of cantaloupe is dependent on cultivar, crop management system, and growing season (Jensen and Malter, 1995; Lorenzo and Castilla, 1995).

With regard to marketable yield, data confirmed that the highest percentage of marketable yield was observed in planting date $15 / 1$ and was significantly different over all other planting dates. While the lowest percentage of marketable yield was shown in planting date $15 / 5$ and was significantly different over all other planting dates. With respect to genotypes, Yathreb 8 had the highest percentage of marketable yield, but it wasn't significantly different from Yathreb 7 and 100. Also, Yathreb 22 ranked second in percentage of marketable yield, but Yathreb 4 gave the lowest percentage of marketable yield and was significantly different over all other hybrids. Concerning to the interaction between planting date and hybrid showed that Yathreb 7, which was grown in planting date 15/1, gave the highest percentage of marketable yield, but it wasn't significantly different in planting dates 15/3, 15/7, from Yathreb 22, which was grown in planting date $15 / 11$, Yathreb 100, which was grown in planting dates 15/3 and 15/11, Yathreb 8, which was grown in planting date 15/3 and Yathreb 4, which was grown in planting date 15/1. On the other side, Yathreb 4, which was grown in planting date 15/5, had the lowest percentage of marketable yield, but it wasn't significantly different in planting dates $15 / 3,15 / 7,15 / 11$, and from Yathreb 22, which was grown in planting dates $15 / 3$ and 15/5. These results are in agreement with Dufault et al. (2006) who found that the earliest recommended planting date with acceptable yield and good internal quality was March 12th for all cultivars. Also, Refai et al. (2008) indicated that there were highly significant differences of the interactions between planting dates and cantaloupe hybrids for total and marketable yield traits.

\section{Fruit Quality}

Obtained data of combined analysis on fruit quality traits during the period from 2016 to 2018 were combined in Tables 4 and 5, and Figures 8, 9, 10 and 11.

Regarding average fruit weight (AFW), the heaviest fruits were produced in planting date $15 / 5$ and was significantly different over all other planting dates. While the lowest AFW was observed in planting date 15/11 and was significantly different over all other planting dates. Referring to genotypes, hybrid Yathreb 8 produced the heaviest fruits and was significantly different over all other hybrids. whereas, hybrid Yathreb 100 ranked as the second in AFW, but it wasn't significantly different from hybrids Yathreb 7 and 22. The least AFW was recorded in hybrid Yathreb 4. Concerning to the interaction between planting date and hybrid showed that Yathreb 8, which was grown in planting date $15 / 5$, gave the heaviest fruits and 
Table 4. The effects of planting date, hybrid and the interaction among them on average fruit weight, seed cavity diameter and flesh thickness during the period from 2016 to 2018 in a combined analysis for two years of each planting date.

\begin{tabular}{|c|c|c|c|c|}
\hline \multirow[t]{2}{*}{ Treatment } & & $\begin{array}{l}\text { Average fruit } \\
\text { weight (gm) }\end{array}$ & $\begin{array}{c}\text { Seed cavity } \\
\text { diameter }(\mathrm{cm})\end{array}$ & $\begin{array}{l}\text { Flesh thickness } \\
(\mathrm{cm})\end{array}$ \\
\hline & & \multicolumn{3}{|c|}{ Planting date } \\
\hline $15 / 3$ & & $909.83 \mathrm{~b}$ & $4.21 \mathrm{c}$ & $3.54 \mathrm{a}$ \\
\hline $15 / 5$ & & $1031.67 \mathrm{a}$ & $4.74 \mathrm{a}$ & $3.07 \mathrm{c}$ \\
\hline $15 / 7$ & & $744.85 \mathrm{~d}$ & $4.44 \mathrm{~b}$ & $3.34 \mathrm{~b}$ \\
\hline $15 / 11$ & & $454.13 \mathrm{e}$ & $3.93 \mathrm{~d}$ & $3.46 a b$ \\
\hline \multirow[t]{2}{*}{$15 / 1$} & & $790.43 \mathrm{c}$ & $4.16 \mathrm{c}$ & $3.49 \mathrm{a}$ \\
\hline & \multicolumn{4}{|c|}{ Genotype } \\
\hline Yathreb 7 & & $800.40 \mathrm{~b}$ & $4.02 \mathrm{c}$ & $3.47 \mathrm{~b}$ \\
\hline Yathreb 8 & & $949.73 \mathrm{a}$ & $4.73 a$ & $3.69 \mathrm{a}$ \\
\hline Yathreb 22 & & $777.54 \mathrm{~b}$ & $3.93 \mathrm{c}$ & $3.48 \mathrm{~b}$ \\
\hline Yathreb 4 & & $590.00 \mathrm{c}$ & $4.42 \mathrm{~b}$ & $2.84 \mathrm{c}$ \\
\hline \multirow[t]{2}{*}{ Yathreb 100} & & $813.23 \mathrm{~b}$ & $4.38 \mathrm{~b}$ & $3.43 \mathrm{~b}$ \\
\hline & \multicolumn{4}{|c|}{ The interaction } \\
\hline Planting date & Hybrid & & & \\
\hline \multirow[t]{5}{*}{$15 / 3$} & Yathreb 7 & $973.75 \mathrm{c}$ & $3.72 \mathrm{klm}$ & $3.69 \mathrm{abcd}$ \\
\hline & Yathreb 8 & $1085.00 \mathrm{~b}$ & 4.43 defg & $3.89 a b$ \\
\hline & Yathreb 22 & 892.75 cdef & 3.86 hijkl & 3.53 cdef \\
\hline & Yathreb 4 & $668.38 \mathrm{i}$ & 4.39 defg & $2.99 \mathrm{ijk}$ \\
\hline & Yathreb 100 & $929.25 \mathrm{cde}$ & $4.68 \mathrm{bcd}$ & 3.62 bcde \\
\hline \multirow[t]{5}{*}{$15 / 5$} & Yathreb 7 & $1105.63 \mathrm{~b}$ & $4.79 \mathrm{bc}$ & $3.01 \mathrm{ijk}$ \\
\hline & Yathreb 8 & $1354.63 \mathrm{a}$ & $5.41 \mathrm{a}$ & 3.49 defg \\
\hline & Yathreb 22 & $946.84 \mathrm{cde}$ & 4.40 defg & 3.09 hijk \\
\hline & Yathreb 4 & $804.50 \mathrm{fg}$ & $4.65 \mathrm{bcd}$ & $2.59 \mathrm{I}$ \\
\hline & Yathreb 100 & 946.75 cde & 4.48 cde & $3.18 \mathrm{ghij}$ \\
\hline \multirow[t]{5}{*}{$15 / 7$} & Yathreb 7 & 816.88 efg & $4.18 \mathrm{efgh}$ & $3.36 \mathrm{efgh}$ \\
\hline & Yathreb 8 & 857.00 efg & $4.91 \mathrm{~b}$ & $3.74 \mathrm{abcd}$ \\
\hline & Yathreb 22 & $697.38 \mathrm{hi}$ & $4.14 \mathrm{fghi}$ & $3.22 \mathrm{fghi}$ \\
\hline & Yathreb 4 & $535.63 \mathrm{j}$ & 4.46 cdef & $2.86 \mathrm{jkl}$ \\
\hline & Yathreb 100 & 817.38 efg & $4.50 \mathrm{cde}$ & 3.51 def \\
\hline \multirow[t]{5}{*}{$15 / 11$} & Yathreb 7 & $299.50 \mathrm{I}$ & $3.62 \mathrm{~lm}$ & 3.46 defg \\
\hline & Yathreb 8 & 504.38 j & 4.46 cdef & 3.68 abcde \\
\hline & Yathreb 22 & $568.00 \mathrm{j}$ & $3.40 \mathrm{~m}$ & $3.97 \mathrm{a}$ \\
\hline & Yathreb 4 & $394.88 k$ & 4.00 hijk & $2.82 \mathrm{kl}$ \\
\hline & Yathreb 100 & $503.88 \mathrm{j}$ & $4.14 \mathrm{fghi}$ & $3.36 \mathrm{efgh}$ \\
\hline \multirow[t]{5}{*}{$15 / 1$} & Yathreb 7 & $806.25 \mathrm{fg}$ & $3.79 \mathrm{jkl}$ & $3.84 \mathrm{abc}$ \\
\hline & Yathreb 8 & $947.6 \mathrm{~cd}$ & 4.46 cdef & 3.62 bcde \\
\hline & Yathreb 22 & $782.75 \mathrm{gh}$ & 3.83 ijkl & 3.61 bcde \\
\hline & Yathreb 4 & $546.63 \mathrm{j}$ & $4.60 \mathrm{bcd}$ & $2.92 \mathrm{ijk}$ \\
\hline & Yathreb 100 & 868.88 defg & $4.11 \mathrm{ghij}$ & $3.48 \mathrm{defg}$ \\
\hline
\end{tabular}

* Mean within a column followed by different letters is significantly different at 0.05 level. 
Table 5. The effects of planting date, hybrid and the interaction among them on fruit shape index, fruit netting percentage and total soluble solids during the period from 2016 to 2018 in a combined analysis for two years of each planting date.

\begin{tabular}{|c|c|c|c|c|}
\hline Treatment & & FSI & $\begin{array}{l}\text { Netting } \\
(\%)\end{array}$ & $\begin{array}{l}\begin{array}{l}\text { TSS } \\
(\%)\end{array} \\
\end{array}$ \\
\hline & & \multicolumn{3}{|c|}{ Planting date } \\
\hline $15 / 3$ & & $0.98 \mathrm{a}$ & $100.00 \mathrm{a}$ & $12.87 \mathrm{a}$ \\
\hline $15 / 5$ & & $0.92 \mathrm{~b}$ & $90.88 \mathrm{c}$ & $9.79 \mathrm{c}$ \\
\hline $15 / 7$ & & $0.97 a$ & $100.00 \mathrm{a}$ & $12.12 \mathrm{~b}$ \\
\hline $15 / 11$ & & $0.98 \mathrm{a}$ & $100.00 \mathrm{a}$ & $12.95 \mathrm{a}$ \\
\hline \multirow{2}{*}{$15 / 1$} & & $0.97 \mathrm{a}$ & $97.21 \mathrm{~b}$ & $12.86 \mathrm{a}$ \\
\hline & & \multicolumn{2}{|c|}{ Genotype } & \\
\hline Yathreb 7 & & $0.96 \mathrm{~b}$ & $98.68 \mathrm{a}$ & $12.00 \mathrm{c}$ \\
\hline Yathreb 8 & & $1.11 \mathrm{a}$ & $100.00 \mathrm{a}$ & $11.42 \mathrm{~d}$ \\
\hline Yathreb 22 & & $0.96 \mathrm{~b}$ & $92.83 \mathrm{c}$ & $12.86 \mathrm{~b}$ \\
\hline Yathreb 4 & & $0.95 \mathrm{~b}$ & $96.58 \mathrm{~b}$ & $10.78 \mathrm{e}$ \\
\hline \multirow[t]{2}{*}{ Yathreb 100} & & $0.84 \mathrm{c}$ & $100.00 \mathrm{a}$ & $13.53 \mathrm{a}$ \\
\hline & & \multicolumn{2}{|c|}{ The interaction } & \\
\hline Planting date & Hybrid & & & \\
\hline \multirow{5}{*}{$15 / 3$} & Yathreb 7 & $0.97 \mathrm{fgh}$ & $100.00 \mathrm{a}$ & $13.47 \mathrm{abc}$ \\
\hline & Yathreb 8 & $1.09 \mathrm{bc}$ & $100.00 \mathrm{a}$ & $12.04 \mathrm{fg}$ \\
\hline & Yathreb 22 & $1.04 \mathrm{~cd}$ & $100.00 \mathrm{a}$ & $13.69 \mathrm{ab}$ \\
\hline & Yathreb 4 & $0.97 \mathrm{fgh}$ & $100.00 \mathrm{a}$ & $11.65 \mathrm{ghij}$ \\
\hline & Yathreb 100 & $0.81 \mathrm{~m}$ & $100.00 \mathrm{a}$ & $13.53 \mathrm{abc}$ \\
\hline \multirow[t]{5}{*}{$15 / 5$} & Yathreb 7 & $0.90 \mathrm{ijk}$ & $93.38 \mathrm{~b}$ & 8.15 I \\
\hline & Yathreb 8 & $1.03 \mathrm{de}$ & $100.00 \mathrm{a}$ & $8.79 k$ \\
\hline & Yathreb 22 & $0.92 \mathrm{hij}$ & $70.88 \mathrm{c}$ & $11.06 \mathrm{j}$ \\
\hline & Yathreb 4 & $0.91 \mathrm{ij}$ & $90.13 \mathrm{~b}$ & $7.37 \mathrm{~m}$ \\
\hline & Yathreb 100 & $0.85 \mathrm{klm}$ & $100.00 \mathrm{a}$ & $13.5 \mathrm{ab}$ \\
\hline \multirow[t]{5}{*}{$15 / 7$} & Yathreb 7 & 1.00 def & $100.00 \mathrm{a}$ & $11.63 \mathrm{ghij}$ \\
\hline & Yathreb 8 & $1.12 \mathrm{ab}$ & $100.00 \mathrm{a}$ & $11.21 \mathrm{ij}$ \\
\hline & Yathreb 22 & $0.92 \mathrm{hij}$ & $100.00 \mathrm{a}$ & $12.76 \mathrm{de}$ \\
\hline & Yathreb 4 & $0.97 \mathrm{fgh}$ & $100.00 \mathrm{a}$ & $11.3 \mathrm{hij}$ \\
\hline & Yathreb 100 & $0.84 \mathrm{Im}$ & $100.00 \mathrm{a}$ & $13.7 \mathrm{ab}$ \\
\hline \multirow[t]{5}{*}{$15 / 11$} & Yathreb 7 & $0.97 \mathrm{fgh}$ & $100.00 \mathrm{a}$ & $13.09 \mathrm{bcd}$ \\
\hline & Yathreb 8 & $1.16 \mathrm{a}$ & $100.00 \mathrm{a}$ & $12.67 \mathrm{de}$ \\
\hline & Yathreb 22 & $0.97 \mathrm{fgh}$ & $100.00 \mathrm{a}$ & $13.89 \mathrm{a}$ \\
\hline & Yathreb 4 & $0.93 \mathrm{ghij}$ & $100.00 \mathrm{a}$ & $11.88 \mathrm{fgh}$ \\
\hline & Yathreb 100 & $0.88 \mathrm{jkl}$ & $100.00 \mathrm{a}$ & $13.23 \mathrm{bcd}$ \\
\hline \multirow[t]{5}{*}{$15 / 1$} & Yathreb 7 & $0.97 \mathrm{fgh}$ & $100.00 \mathrm{a}$ & $13.69 a b$ \\
\hline & Yathreb 8 & $1.15 \mathrm{a}$ & $100.00 \mathrm{a}$ & 12.38 ef \\
\hline & Yathreb 22 & 0.95 fghi & $93.25 \mathrm{~b}$ & $12.92 \mathrm{cde}$ \\
\hline & Yathreb 4 & 0.98 efg & $92.79 \mathrm{~b}$ & $11.72 \mathrm{ghi}$ \\
\hline & Yathreb 100 & $0.82 \mathrm{~m}$ & $100.00 \mathrm{a}$ & $13.6 \mathrm{ab}$ \\
\hline
\end{tabular}

* Mean within a column followed by different letters is significantly different at 0.05 level. 


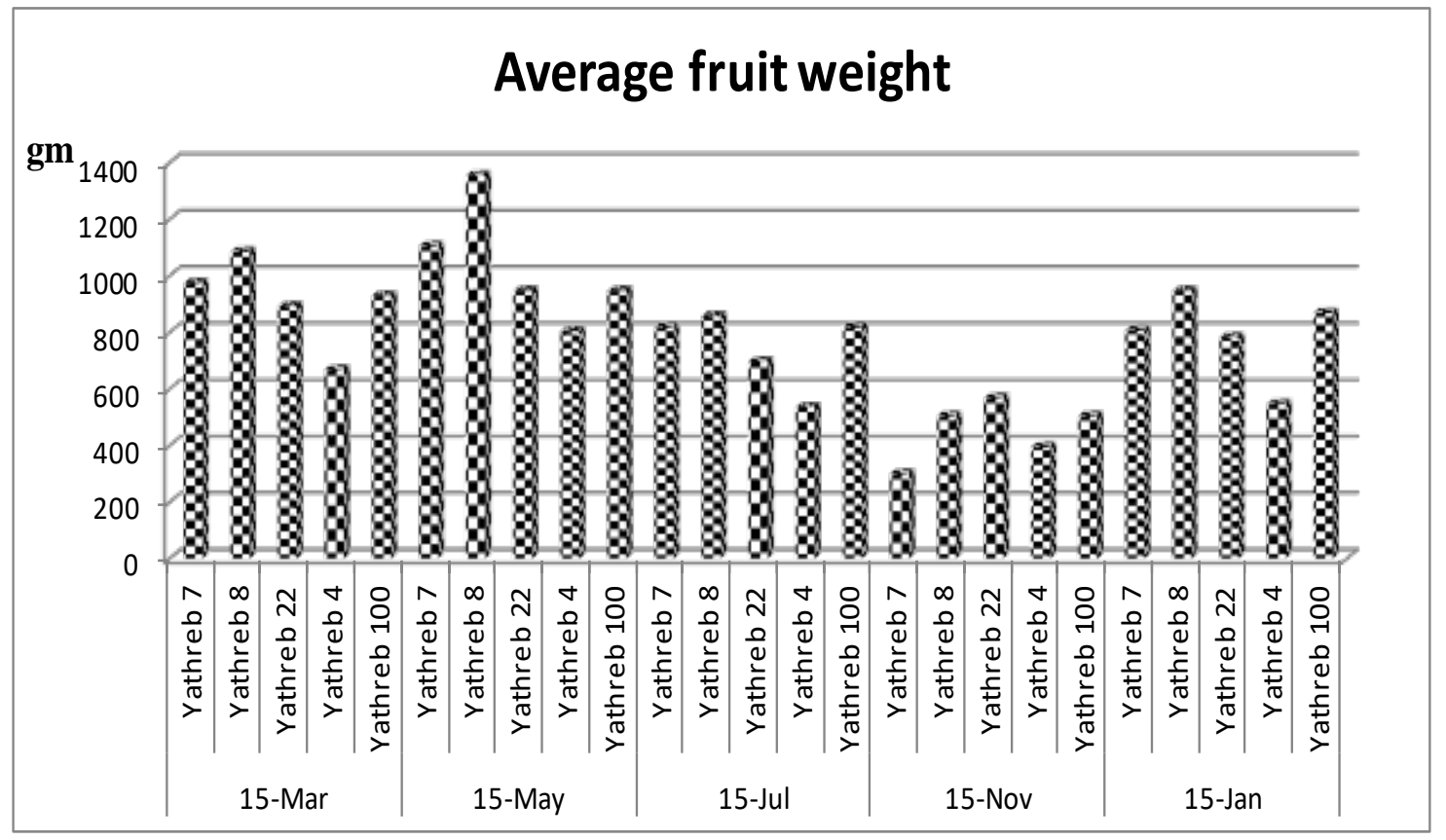

Fig. (8): The effects of the interaction between planting date and hybrid on average fruit weight.

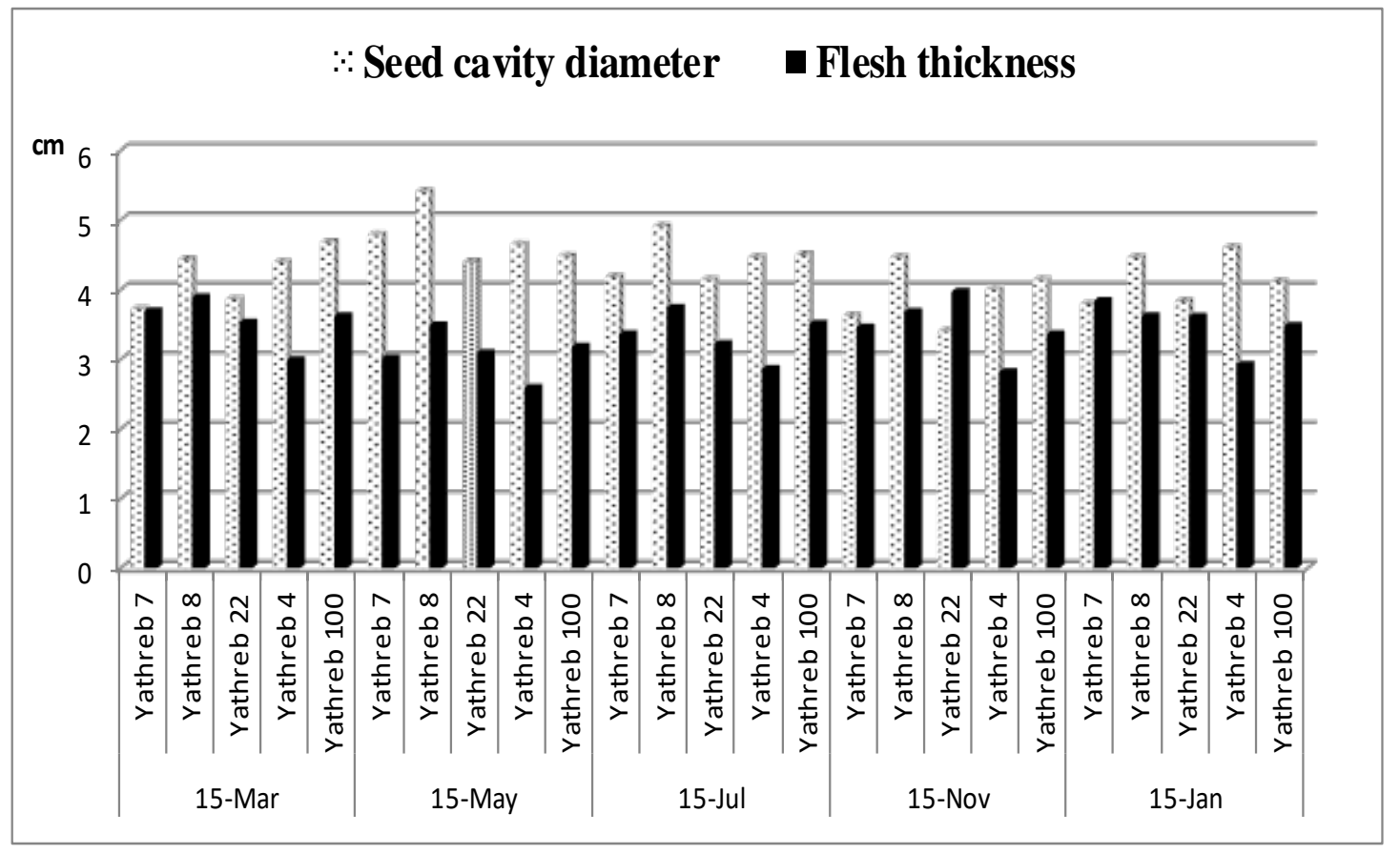

Fig. (9): The effects of the interaction between planting date and hybrid on seed cavity diameter and flesh thickness. 


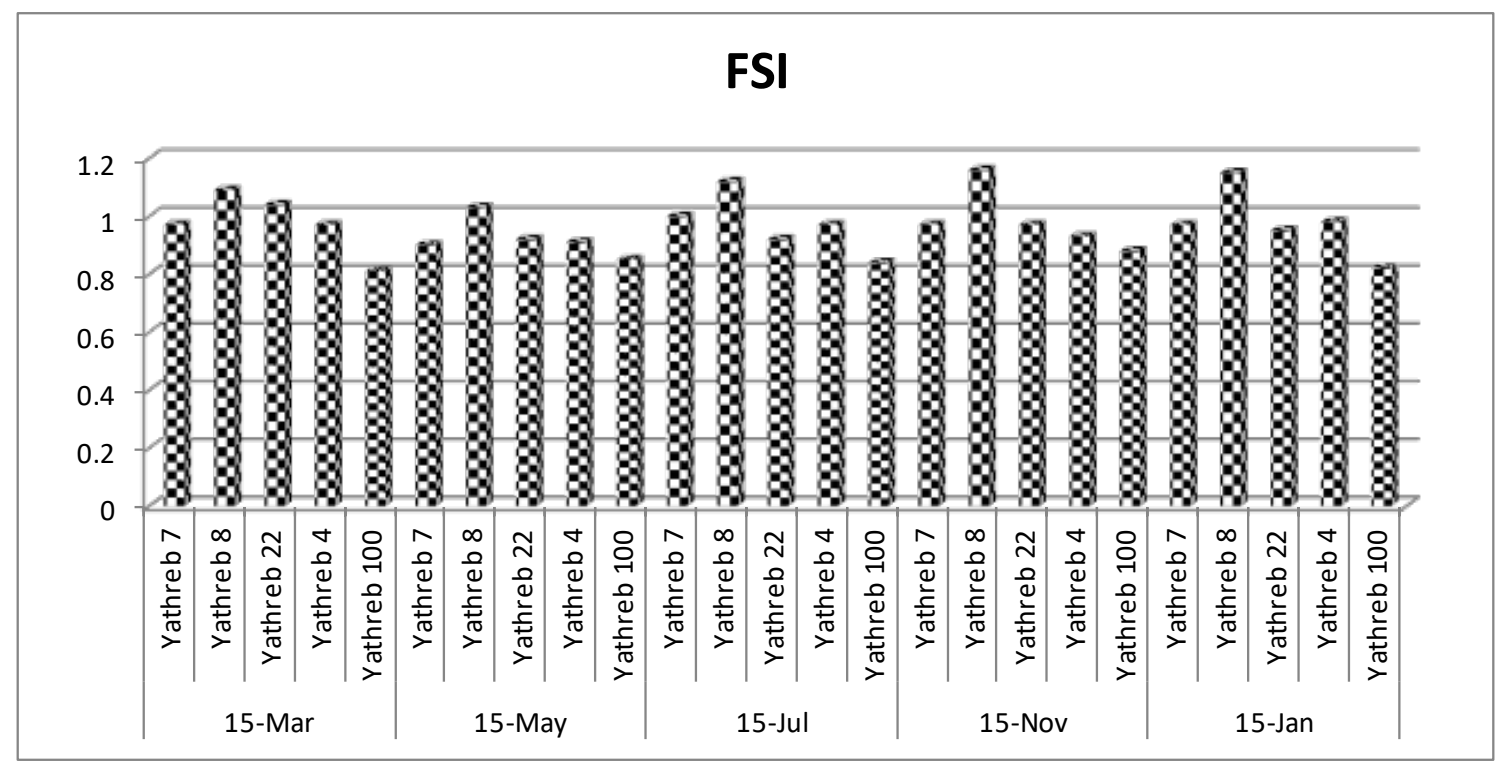

Fig. (10) The effects of the interaction between planting date and hybrid on fruit shape index.

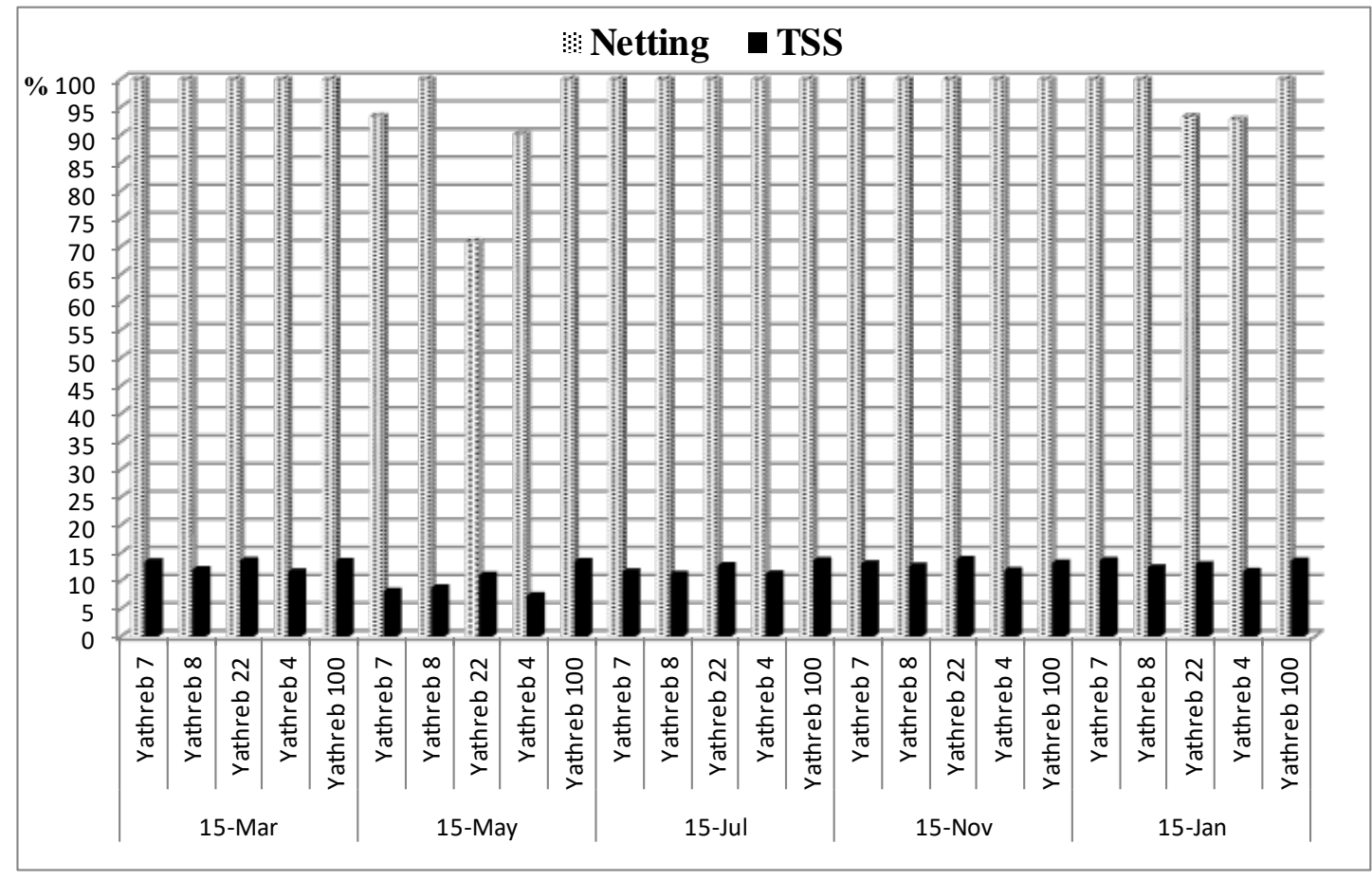

Fig. (11): The effects of the interaction between planting date and hybrid on fruit netting percentage and TSS.

was significantly different over all other treatments. Also, Yathreb 7, which was grown in planting date $15 / 5$, ranked second in AFW, but it wasn't significantly different from Yathreb 8, which was grown in planting date 15/3. The least AFW was shown in Yathreb 4, which was grown in planting date $15 / 11$ and was significantly different over all other treatments. These results are in 
agreement with those of Brandenberger and Wiedenfeld (1997) and García et al. (2006) who reported that the variability of melon hybrids which were grown in different environments resulted in the effect on average fruit weight and fruit quality. This concordance in results due to each genotype has different AFW according to its genome and its reaction with environment.

With respect to seed cavity diameter (SCD), the least SCD was recorded in planting date $15 / 11$ and was significantly different over all other planting dates. While, the largest SCD was observed in planting date $15 / 5$ and was significantly different over all other planting dates. Concerning to genotypes, Yathreb 22 had the lowest SCD, with insignificantly different from Yathreb 7. In contrast, Yathreb 8 had the largest SCD and was significantly different over all other hybrids. Referring to the interaction between planting date and hybrid illustrated that Yathreb 22, which was grown in planting date 15/11, had the least SCD, but it wasn't significantly different from Yathreb 7, which was grown in planting dates $15 / 3$ and 15/11. While Yathreb 8, which was grown in planting date 15/5, had the largest SCD and was significantly different over all other treatments.

Regarding flesh thickness, the thickest flesh was observed in planting date $15 / 3$, with insignificant difference in planting dates $15 / 1$ and 15/11. The thinnest flesh was recorded in planting date $15 / 5$ and was significantly different over all other planting dates. With regard to genotypes, the hybrid Yathreb 8 had the thickest flesh and was significantly different over all other hybrids. Also, the hybrid Yathreb 22 is ranked as the second in this trait, but it wasn't significantly different from hybrids Yathreb 7 and 100. On the contrary, hybrid Yathreb 4 had the thinner flesh and was significantly different over all other hybrids. Concerning to the the interaction between planting date and hybrid illustrated that hybrid Yathreb 22, which was grown in planting date 15/11, had the thickest flesh. It wasn't significantly different from hybrids Yathreb 7 and 8, which were grown in planting date 15/3, hybrid Yathreb 8, which was grown in planting dates $15 / 7$ and 15/11 and hybrid Yathreb 7, which was grown in planting date 15/1. On the other hand, hybrid Yathreb 4, which was grown in planting date 15/5, had the thinnest flesh. Also, it wasn't significantly different in planting dates 15/7 and 15/11. These results are disagree with Refai et al. (2008) who reported that there was no significant difference between cantaloupe hybrids, planting dates and the interaction between them in flesh thickness.

Concerning to fruit shape index (FSI), the highest value was observed in planting date $15 / 3$, but it wasn't significantly different from planting dates $15 / 7,15 / 11$ and 15/1. While the lowest value of FSI was measured in planting date $15 / 5$ and was significantly different over all other planting dates. With regard to genotypes, hybrid Yathreb 8 had the highest value of FSI and was significantly different over all other hybrids. In addition, hybrids Yathreb 22, 7 and 4 ranked second in this trait and had round fruits. On the contrary, Yathreb 100 had the least value of FSI and was significantly different over all other hybrids. Regarding the interaction between planting date and hybrid indicated that hybrid Yathreb 8, which was grown in planting date 15/11, had the highest value of FSI. While it wasn't significantly different in planting dates 15/1 and 15/7. In contrast, hybrid Yathreb 100 , which was grown in planting date $15 / 3$, had the least value of FSI. While it wasn't significantly different in planting dates 15/1, 15/5 and 15/7. These results 
are in agreement with Refai et al. (2008) who found that there were significant differences of the interaction between planting dates and cantaloupe hybrids in fruit length trait.

Regarding netting percentage, the highest value was shown in planting date $15 / 3$, but it wasn't significantly different from planting dates $15 / 7$ and 15/11. The lowest value of netting percentage was observed in planting date $15 / 5$ and was significantly different over all other planting dates. With respect to genotypes, hybrid Yathreb 8 had the highest value of netting percentage, but it wasn't significantly different from hybrids Yathreb 100 and 7. On the other hand, hybrid Yathreb 22 had the least value of netting percentage and was significantly different over all other hybrids. Concerning the interaction between planting date and hybrid indicated that hybrid Yathreb 7, which was grown in planting date $15 / 3$, had the highest percentage of netting. While it wasn't significantly different from most of other treatments. In contrast, hybrid Yathreb 22, which was grown in planting date 15/5, had the least percentage of netting and was significantly different over all other treatments.

Concerning the total soluble solids (TSS), the highest TSS value was shown in planting date 15/11, but it wasn't significantly different from planting dates $15 / 3$ and 15/1. On the contrary, the lowest TSS was determined in planting date $15 / 5$ and was significantly different over all other planting dates. With respect to genotypes, hybrid Yathreb 100 had the highest TSS and was significantly different over all other genotypes. Also, hybrid Yathreb 22 ranked second in TSS. In contrast, hybrid Yathreb 4 had the lowest TSS and was significantly different over all other genotypes. Concerning the interaction between planting date and hybrid indicated that hybrid Yathreb 22, which was grown in planting date 15/11, had the highest TSS, but it wasn't significantly different from most of other treatments. On the contrary, hybrid Yathreb 4, which was grown in planting date 15/5, had the least TSS and was significantly different over all other treatments. These results are in agreement with Refai et al. (2008) who found that planting of cantaloupe hybrid "Rafegal(c-8)" in 15 of July was the best for total soluble solids (TSS). So, they reported that there were significant differences of the interaction between planting dates and cantaloupe hybrids in TSS trait. In our study, the highest TSS was in planting date $15 / 11$ may be due to low temperatures during fruit formation in this planting date, but the lowest TSS was in planting date $15 / 5$ may be due to high temperatures during fruit formation in this planting date. So, this explanation is in agreement with Welles and Buitelaar (1988) who found that any factor that shortens the period from flowering to fruit maturity like high temperatures also reduced muskmelon soluble solids.

\section{Chemical Determinations}

Combined analysis of data concerning chemical determinations are shown in Table 6 and Figures 12 and 13.

Regarding leaves dry matter (LDM) percentage, the highest LDM percentage was determined in planting date 15/11 and was significantly different over all other planting dates. In contrast, the least LDM percentage was recorded in planting date $15 / 5$ and was significantly different over all other planting dates. Concerning to genotypes, hybrid Yathreb 100 had the highest LDM percentage and was significantly different over all other genotypes. In addition, hybrid Yathreb 22 ranked second in this trait and was significantly different over all other genotypes. On the contrary, hybrid Yathreb 4 had the least LDM percentage, but it wasn't significantly different from 
Table 6. The effects of planting date, hybrid and the interaction among them on percentage of LDM, FDM, total and reduced sugars content during the period from 2016 to 2018 in a combined analysis for two years of each planting date.

\begin{tabular}{|c|c|c|c|c|c|}
\hline \multirow[t]{2}{*}{ Treatment } & & $\begin{array}{l}\text { LDM } \\
\text { (\%) }\end{array}$ & $\begin{array}{l}\text { FDM } \\
(\%)\end{array}$ & $\begin{array}{c}\text { Total } \\
\text { sugars } \\
\text { content }\end{array}$ & $\begin{array}{c}\text { Reduced } \\
\text { sugars } \\
\text { content (\%) }\end{array}$ \\
\hline & \multicolumn{5}{|c|}{ Planting date } \\
\hline $15 / 3$ & & $22.01 \mathrm{C}$ & $10.70 \mathrm{c}$ & $23.32 \mathrm{~b}$ & $15.84 \mathrm{c}$ \\
\hline $15 / 5$ & & $18.72 \mathrm{~d}$ & $8.34 \mathrm{e}$ & $16.38 \mathrm{~d}$ & $9.93 \mathrm{e}$ \\
\hline $15 / 7$ & & $21.50 \mathrm{c}$ & $10.28 \mathrm{~d}$ & $19.60 \mathrm{c}$ & $14.31 \mathrm{~d}$ \\
\hline $15 / 11$ & & $27.67 \mathrm{a}$ & $11.84 \mathrm{a}$ & $27.68 \mathrm{a}$ & $20.65 a$ \\
\hline $15 / 1$ & & $24.11 \mathrm{~b}$ & $11.06 \mathrm{~b}$ & $23.94 \mathrm{~b}$ & $17.51 \mathrm{~b}$ \\
\hline \multicolumn{6}{|c|}{ Genotype } \\
\hline Yathreb 7 & & $21.32 \mathrm{~cd}$ & $10.47 \mathrm{~b}$ & $21.36 \mathrm{bc}$ & $14.42 \mathrm{c}$ \\
\hline Yathreb 8 & & $21.58 \mathrm{c}$ & $9.51 \mathrm{c}$ & $20.63 \mathrm{C}$ & $13.89 \mathrm{c}$ \\
\hline Yathreb 22 & & 23.74 b & $10.61 \mathrm{~b}$ & $22.53 \mathrm{~b}$ & $16.37 \mathrm{~b}$ \\
\hline Yathreb 4 & & $20.23 \mathrm{~d}$ & $9.57 \mathrm{c}$ & $18.96 \mathrm{~d}$ & $12.51 \mathrm{~d}$ \\
\hline Yathreb & & $27.15 \mathrm{a}$ & $12.07 \mathrm{a}$ & $27.44 \mathrm{a}$ & $21.05 \mathrm{a}$ \\
\hline \multicolumn{6}{|c|}{ The interaction } \\
\hline Planting & Hybrid & & & & \\
\hline \multirow[t]{5}{*}{$15 / 3$} & Yathreb 7 & $21.29 \mathrm{fgh}$ & 10.99 efgh & 23.19 efghi & $15.45 \mathrm{fgh}$ \\
\hline & Yathreb 8 & 22.78 ef & 9.86 jkl & 21.39 hijk & $13.41 \mathrm{ijk}$ \\
\hline & Yathreb 22 & $21.21 \mathrm{fgh}$ & 10.96 efgh & 23.00 efghi & $16.77 \mathrm{fg}$ \\
\hline & Yathreb 4 & $19.34 \mathrm{hi}$ & $9.73 \mathrm{kl}$ & $20.52 \mathrm{ijkl}$ & $11.80 \mathrm{kl}$ \\
\hline & Yathreb 100 & $25.44 \mathrm{~cd}$ & $11.97 \mathrm{bcd}$ & $28.48 \mathrm{~b}$ & 21.79 bc \\
\hline \multirow[t]{5}{*}{$15 / 5$} & Yathreb 7 & $15.37 \mathrm{j}$ & $7.96 \mathrm{~m}$ & 13.95 op & $5.75 n$ \\
\hline & Yathreb 8 & $17.42 \mathbf{i j}$ & $6.94 n$ & 15.36 no & $7.82 \mathrm{~m}$ \\
\hline & Yathreb 22 & $16.14 \mathrm{j}$ & $7.47 \mathrm{mn}$ & 14.41 op & $8.21 \mathrm{~m}$ \\
\hline & Yathreb 4 & $17.13 \mathbf{i j}$ & $7.11 n$ & $11.87 \mathrm{p}$ & $7.23 \mathrm{mn}$ \\
\hline & Yathreb 100 & $27.55 \mathrm{bc}$ & $12.21 \mathrm{abc}$ & $26.32 \mathrm{bcd}$ & $20.66 \mathrm{~cd}$ \\
\hline \multirow[t]{5}{*}{$15 / 7$} & Yathreb 7 & $19.33 \mathrm{hi}$ & $10.15 \mathrm{ijkl}$ & $18.78 \mathrm{klm}$ & $13.96 \mathrm{hij}$ \\
\hline & Yathreb 8 & $19.99 \mathrm{gh}$ & $9.54 \mathrm{I}$ & $18.80 \mathrm{jkIm}$ & $12.80 \mathrm{jkl}$ \\
\hline & Yathreb 22 & 22.53 ef & 10.36 hijk & $18.21 \mathrm{Imn}$ & $14.25 \mathrm{hij}$ \\
\hline & Yathreb 4 & $19.92 \mathrm{gh}$ & 9.85 jkl & $15.99 \mathrm{mno}$ & $11.16 \mathrm{I}$ \\
\hline & Yathreb 100 & $25.74 \mathrm{~cd}$ & $11.52 \mathrm{cde}$ & $26.21 \mathrm{bcd}$ & $19.38 \mathrm{~d}$ \\
\hline \multirow[t]{5}{*}{$15 / 11$} & Yathreb 7 & $26.69 \mathrm{bc}$ & $12.09 \mathrm{bc}$ & $27.20 \mathrm{bc}$ & $20.17 \mathrm{~cd}$ \\
\hline & Yathreb 8 & $25.52 \mathrm{~cd}$ & 10.87 efghi & $25.37 \mathrm{cde}$ & $18.96 \mathrm{de}$ \\
\hline & Yathreb 22 & $33.12 \mathrm{a}$ & $12.93 \mathrm{a}$ & $32.28 \mathrm{a}$ & $23.73 \mathrm{a}$ \\
\hline & Yathreb 4 & $23.91 \mathrm{de}$ & $10.66 \mathrm{fghi}$ & 24.66 cdefg & 17.17 ef \\
\hline & Yathreb 100 & $29.12 \mathrm{~b}$ & $12.64 \mathrm{ab}$ & $28.88 \mathrm{~b}$ & $23.21 a b$ \\
\hline \multirow[t]{5}{*}{$15 / 1$} & Yathreb 7 & $23.90 \mathrm{de}$ & 11.14 efg & 23.66 defgh & $16.79 \mathrm{fg}$ \\
\hline & Yathreb 8 & $22.22 \mathrm{efg}$ & 10.36 hijk & 22.25 fghi & $16.47 \mathrm{fg}$ \\
\hline & Yathreb 22 & $25.68 \mathrm{~cd}$ & $11.31 \mathrm{def}$ & 24.74 cdef & $18.89 \mathrm{de}$ \\
\hline & Yathreb 4 & $20.84 \mathrm{fgh}$ & $10.49 \mathrm{ghij}$ & 21.74 ghij & $15.20 \mathrm{ghi}$ \\
\hline & Yathreb 100 & $27.90 \mathrm{bc}$ & $12.01 \mathrm{bcd}$ & $27.31 \mathrm{bc}$ & $20.21 \mathrm{~cd}$ \\
\hline
\end{tabular}

* Mean within a column followed by different letters is significantly different at 0.05 level. 


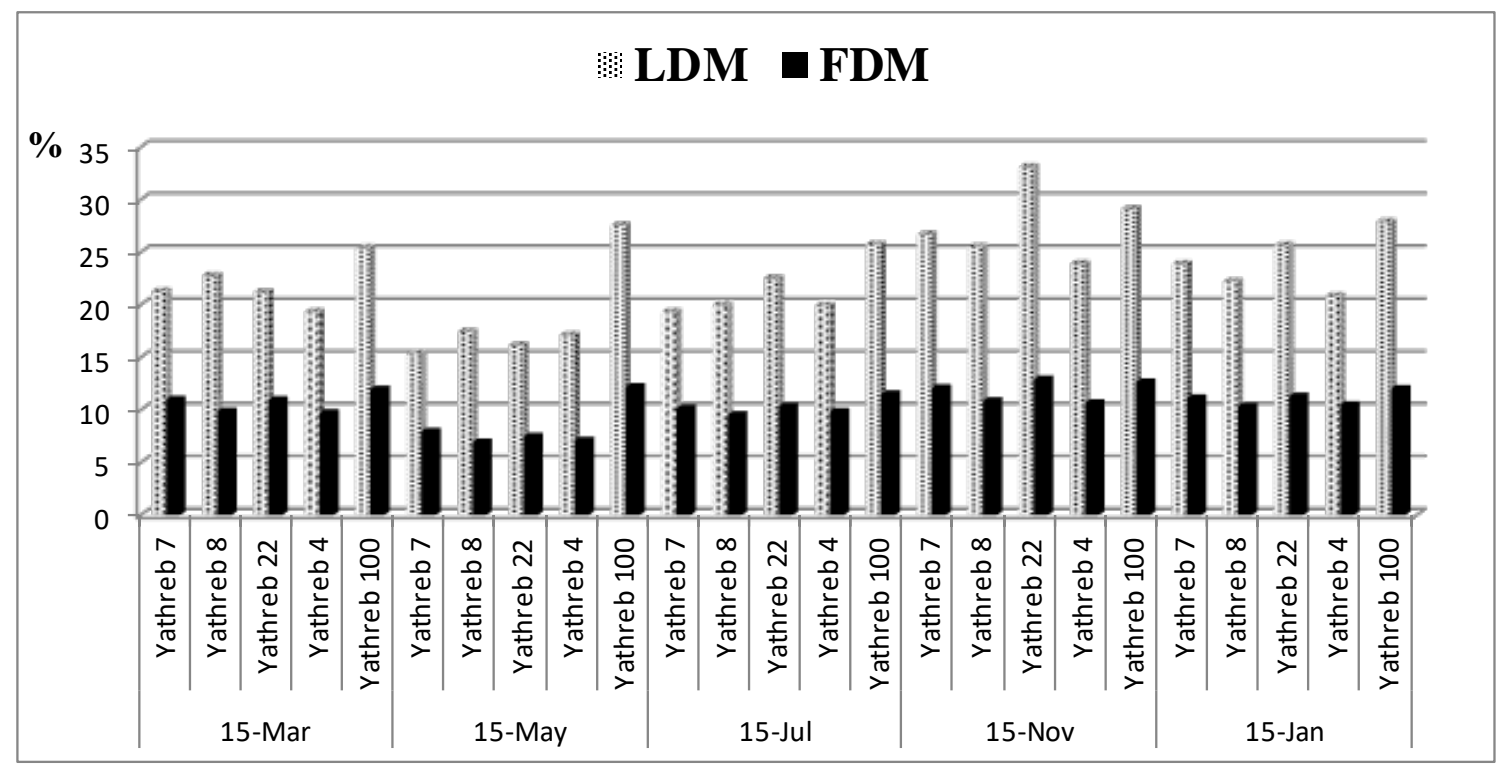

Fig. (12) The effects of the interaction between planting date and hybrid on LDM and FDM.

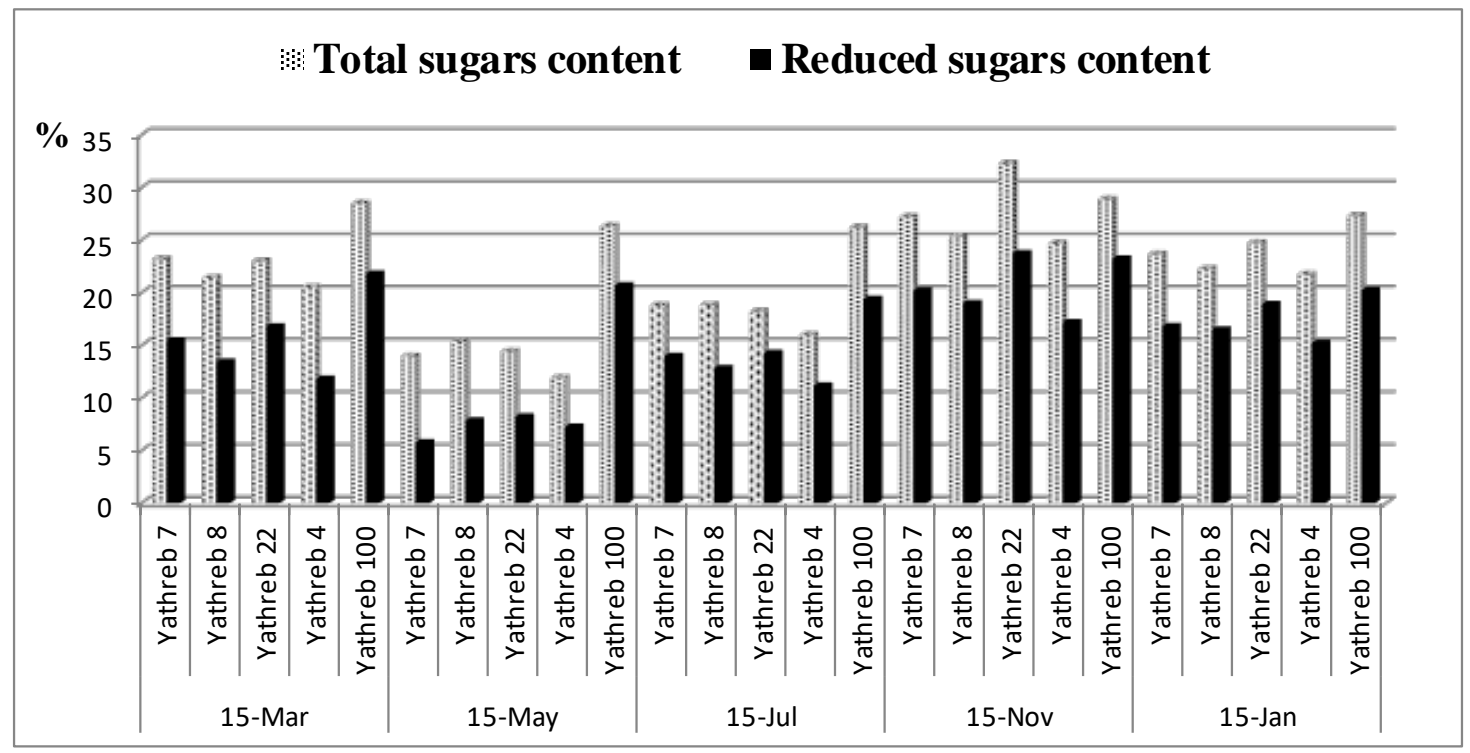

Fig. (13): The effects of the interaction between planting date and hybrid on total and reduced sugars content.

hybrid Yathreb 7. With respect to the interaction between planting date and hybrid indicated that hybrid Yathreb 22, which was grown in planting date 15/11, had the highest LDM percentage and was significantly different over all other treatments. Also, Yathreb 100, which was grown in planting date 15/11, ranked second in this trait, but it wasn't significantly different in planting dates
15/1 and 15/5. In addition, hybrid Yathreb 7 which was grown in planting date 15/11. On the contrary, hybrid Yathreb 7, which was grown in planting date $15 / 5$, had the least LDM percentage, but it wasn't significantly different from hybrids Yathreb 22, 4 and 8, which were grown in the same planting date. These results are in agreement with Mohamedian et al. (2013) who found that there were 
significant differences between local cantaloupe hybrids in LDM, which were grown in planting date 15/3 during 2009 and 2010 in the open field.

Concerning to flesh dry matter (FDM), the highest FDM percentage was shown in planting date 15/11 and was significantly different over all other planting dates. In contrast, the least FDM percentage was recorded in planting date $15 / 5$, and was significantly different over all other planting dates. With regard to genotypes, hybrid Yathreb 100 had the highest FDM percentage and was significantly different over all other genotypes. Also, hybrid Yathreb 22 ranked second, but it wasn't significantly different from hybrid Yathreb 7. On the contrary, hybrid Yathreb 8 had the least FDM percentage, but it wasn't significantly different from hybrid Yathreb 4. Referring to the interaction between planting date and hybrid indicated that hybrid Yathreb 22, which was grown in planting date 15/11, had the highest FDM percentage, but it wasn't significantly different from hybrid Yathreb 100, which was grown in the same planting date and 15/5. Likewise, hybrid Yathreb 100, which was grown in planting date 15/11, ranked second in this trait, but it wasn't significantly different in planting dates $15 / 5,15 / 1$ and $15 / 3$, in addition to hybrid Yathreb 7, which was grown in planting date 15/11. On the other hand, hybrid Yathreb 8, which was grown in planting date $15 / 5$, had the least FDM percentage without significant differences from hybrids Yathreb 4 and 22, which was grown in the same planting date. These results are disagree with Mohamedian et al. (2013) who found that there weren't significant differences between local cantaloupe hybrids in FDM. Also, there were no significant differences between all tested local cantaloupe hybrids in the percentage of FDM, which were grown in planting date 15/3 during 2009 and 2010 in the open field.
With respect to total and reduced sugars content, the highest total and reduced sugars content were detected in planting date 15/11 and was significantly different over all other planting dates. While the lowest total and reduced sugars content were recorded in planting date $15 / 5$ and was significantly different over all other planting dates. Referring to genotypes, hybrid Yathreb 100 gave the highest total and reduced sugars content and was significantly different over all other genotypes. Also, hybrid Yathreb 22 ranked second in both of two traits without significant differences from hybrid Yathreb 7 in total sugars content only. In contrast, hybrid Yathreb 4 gave the lowest total and reduced sugars content and was significantly different over all other genotypes. Concerning to the interaction between planting date and hybrid indicated that hybrid Yathreb 22, which was grown in planting date 15/11, gave the highest total and reduced sugars content without significant differences from hybrid Yathreb 100, which was grown in the same planting date in reduced sugars content only. In addition, Yathreb 100, which was grown in planting date 15/11, ranked second in total and reduced sugars content, it wasn't significantly different in planting date 15/3 in both of the two traits. Also, the total sugars content only of this hybrid wasn't significantly different in planting dates 15/5, $15 / 7$ and 15/1, in addition, hybrid Yathreb 7, which was grown in planting date 15/11. In contrast, hybrid Yathreb 4, which was grown in planting date 15/5, had the lowest total sugars content without significant differences from hybrids Yathreb 7 and 22, which was grown in the same planting date. With respect to the lowest reduced sugars content was determined in Yathreb 7, which was grown in planting date 15/5 without significant differences from hybrid Yathreb 4, which was grown in the same planting date. 
These results are in agreement with Mohamedian et al. (2013) who found that hybrid Yathreb 100 produced the highest values of total and reduced sugars content and was significantly different from all other hybrids. Also, Refai et al. (2008) found that planting of cantaloupe hybrid "Rafegal(c-8)" in 15 of July was the best for total sugars content.

Finally, the obtained results of fruit quality confirmed that the temperature is the major factor which effects on cantaloupe fruit quality, where low temperatures such as during 15/11 improve the fruit quality due to the photosynthesis rate of plant is larger than the respiration rate of plant, while high temperatures such as during 15/5 reduce fruit quality due to the respiration rate of plant is larger than the photosynthesis rate of plant. These explanation of results coincided with those of Pratt (1971), Beaulieu and Grimm (2001), Beaulieu et al. (2004), Beaulieu and Lancaster (2007), Refai et al. (2008), Hakojärvi et al. (2010) who reported that the temperature has the strongest impact on all plant growth stages as compared with other environmental factors. So, changes in fruit melon quality are the result of complex genetical, physiological and environmental influences. Additionally, the interaction between genotype and environmental factors has a great effect on the fruit melon quality.

In conclusion, each hybrid has its own best planting date, which give the best performance in this planting date. The present study showed the best planting date for Yathreb 7 and 8 are 15/1 and 15/3; Yathreb 22 are 15/1 and 15/11; Yathreb 100 are 15/3, 15/5 and 15/7 and Yathreb 4 was 15/3 only.

\section{REFERENCES}

Amuyunzu, P.A., J.A. Chweya, Y. Rosengartner and $S$. Mendlinger
(1997). Effect of different temperature regimes on vegetative growth of melon plants. Afr. Crop Sci. J., 5: 7786.

Baker, J.T. and V.R. Reddy (2001). Temperature effects on phenological development and yield of muskmelon. Ann. Bot., 87: 605-613.

Beaulieu, J. C. and C. C. Grimm (2001). Identification of volatile compounds in cantaloupe at various developmental stages using solid phase microextraction. J. Agric. Food Chem., 49 (3): 1345-1352.

Beaulieu, J. C., D. A. Ingram, J. M. Lea and K. L. Bett-Garber (2004). Effect of harvest maturity on the sensory characteristics fresh-cut cantaloupe. J. Food Sci., 69 (7) : S250-S258.

Beaulieu, J. C. and V. A. Lancaster (2007). Correlating volatile compounds, sensory attributes and quality parameters in stored fresh-cut cantaloupe. J. Agric. Food Chem., 55 (23) : 9503-9513.

Brandenberger, L.P. and R.P. Wiedenfeld (1997). Effects of plant density, row arrangement and cultivar on fruit size and yield in honeydew melons. HortScience, 32 (3): 463 p.

Bruton, B.D., T.K. Hartz and E.L. Cox. (1985). Vine decline in cantaloupes as influenced by cultivar and planting date. Hort-Science, 20: 899-901.

Dubois, M., K.A. Gilles, J.K. Hamilton, P.A. Rebers and F. Smith (1956). Colorimetric method for determination of sugars and related substances. Anal. Chem., 28 (3): 350-356.

Dufault, R.J., A. Korkmaz, B.K. Ward and R.L. Hassell (2006). Planting date and cultivar affect melon quality and productivity. HortScience, 41 (7) : pp. 1559-1564.

García, J.C., Z.F. Rodríguez and J.G. Lugo (2006). Effects of cultivars and plant spacing on performance agronomics and muskmelon yield. Rev. Fac. Agron. (LUZ), 23: 440-449. 
Gomez, A.K. and A.A. Gomez (1984). Statistical Procedures for Agricultural Research. 2nd ed. John Wiley \& Sons Pub., pp. 139-153.

Hakojärvi, M., M. Hautala, J. Ahokas, T. Oksanen, T. Maksimow, A. Aspiala and A. Visala (2010). Platform for simulation of automated crop production. Agron. Res., 8 (1): 797806.

Hussein, A. H. and M. A. M. Selim (2014). Breeding for improving quality and yield characteristics in cantaloupe under high temperature conditions. Egypt. J. Plant Breed., 18(2): 243 264.

Jenni, S., D.C. Cloutier, G. Bourgeois and K.A. Stewart (1996). A heat unit model to predict growth and development of muskmelon to anthesis of perfect flower. J. Am. Soc. Hort. Sci., 121(2): 274-280.

Jensen, M.H. and A.J. Malter (1995). Protected agriculture : A global review. World Bank technical paper, no. 253. The World Bank, Washington, DC.

Koch, Gary G. and P. K. Sen (1968). Some aspects of the statistical analysis of the mixed mode.1. Biometrics, 24: 27 48.

Lee, J., J. Lee, J. Ku, W. Kim and Y. Om. (1998). Cultivars and planting date for August production of cantaloupe (Cucumis melo) in alpine area. RDA. J. Hort. Sci., 40: 31-36.

Lorenzo, P. and N. Castilla (1995). Bell pepper yield response to plant density and radiation in unheated plastic greenhouse. Acta Hort., 412 : 330-335.

McGlashan, D.H. and W.J. Fielding (1990). Effects of planting date and spacing on yield of cantaloupe cultivars at Bodles, Jamaica. Proc. Interamerican Soc. Tropical Hort., 34: 71-72.

Mohamedian, S.A., M.A.M. Selim and F.S.S. Alian (2013). Impact of plant spacing and density on yield and quality of newly local developed cantaloupe $F_{1}$ hybrids. Annals of Agric. Sci., Moshtohor, 51 (4): 391-401.

Nandpuri, K.S. and T. Lai (1978). Varietal response to date of planting in cantaloupe. Veg. Sci,. 5: 8-14.

Pardossi, A., P. Giacomet, F. Malorgio, F.M. Albini, C. Murelli, G. Serra, P. Vernieri and F. Tognoni (2000). The influence of growing season on fruit yield and quality of greenhouse melon (Cucumis melo L.) grown in nutrient film technique in a Mediterranean climate. J. Hort. Sci. Biotechn., 75(4): 488-493.

Pratt, H. (1971). Melons. The biochemistry of fruits and their products. NY: Acadamic Press, pp. 207-232.

Rashidi, M. and K. Seyfi (2007). Classification of fruit shape in cantaloupe using the analysis of geometrical attributes. World Journal of Agricultural Sciences, 3 (6): 735740.

Refai, E. F. S., M. H. Hosseny and A. S. Badawy (2008). Effect of planting dates on yield and quality of two cantaloupe hybrids under assiut conditions. Ass. Univ. Bull. Environ. Res., 11 (2) : 13-25.

Russo, V.M., B.D. Bruton and T. Popham (2002). Genitic factors and production methods that affect yield and quality of vegetable crops. United States Department of Agriculture USDA. Agriculture Research Service Project Number: 6222-21220-002-00., pp. 393403.

Ventura, Y. and S. Mendlinger (1999). Effects of suboptimal low temperature on yield, fruit appearance and quality in muskmelon (Cucumis melo L.) cultivars. J. Hort. Sci. Biotech.,74: 602-607.

Welles, G. W. and K. Buitelaar. (1988). Factors affecting soluble solids content of cantaloupe (Cucumis melo L.). Netherlands J. Agr. Sci., 36: 239246. 
التفاعل بين الظروف البيئية والتعبير الوراثى للهجن المحلية المستنبطة حديثا من الكنتالوب Cucumis melo var.cantaloupensis

محمد أبو الفتوح سليم(') ، فاطمة سليمان سلامة عليان(")

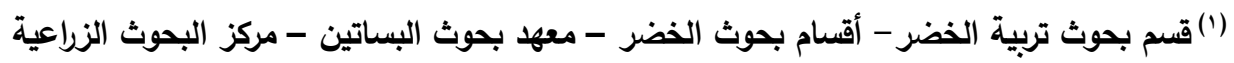

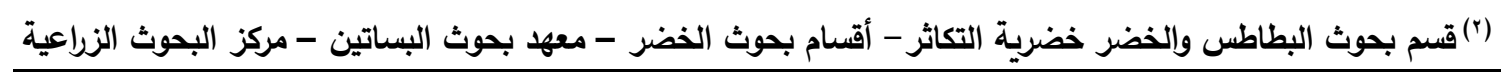

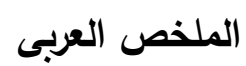

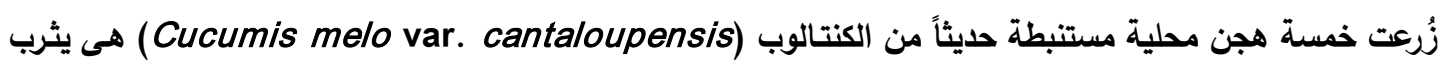

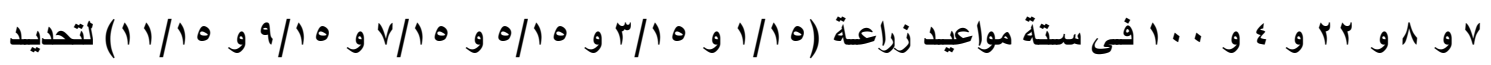

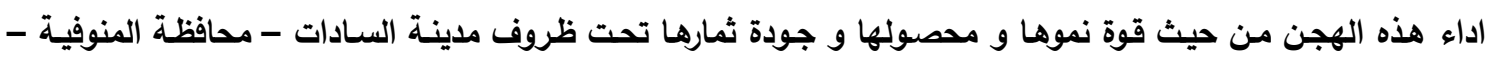

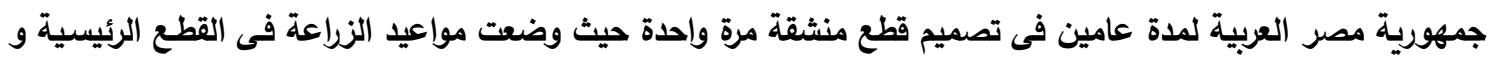

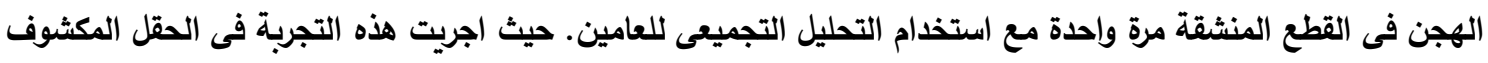

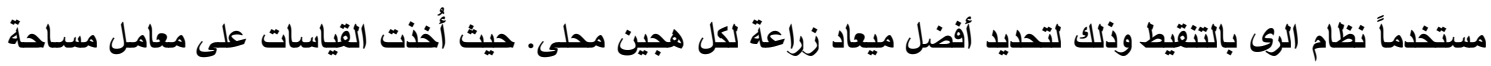

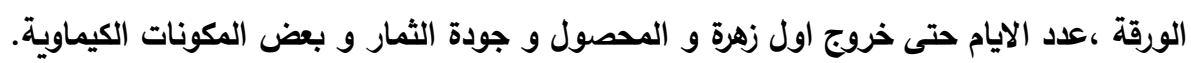

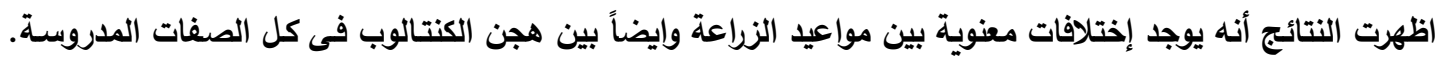

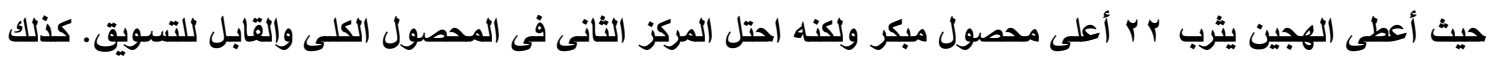

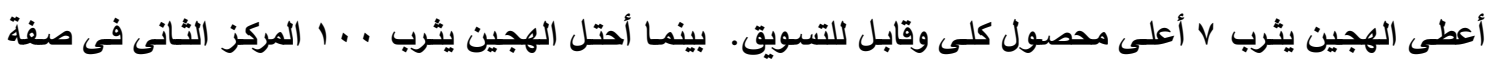
الدحصول الكلى والمركز الأول فى صفة المحصول القابل للتسويق. كنلك أعطت هذه الهُ الهجن أعلى القيم لكثير من الصفات

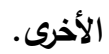

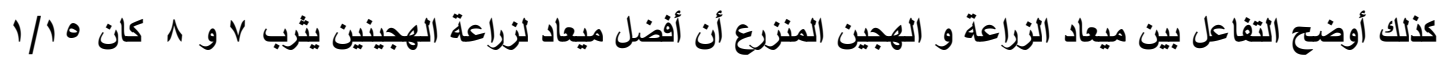

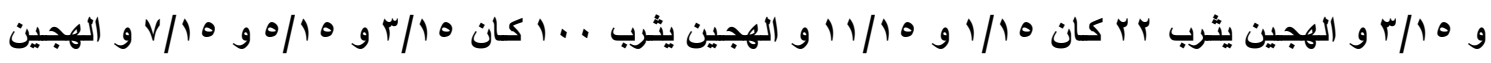

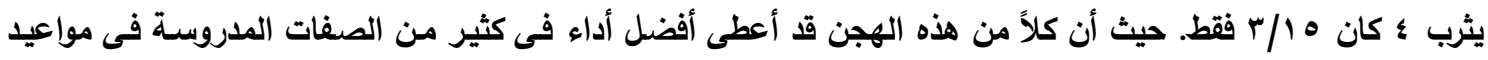

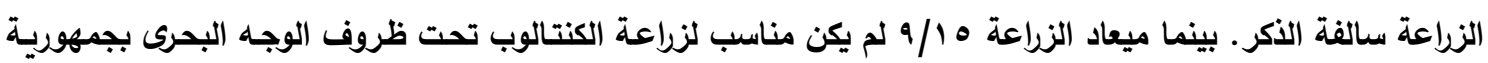

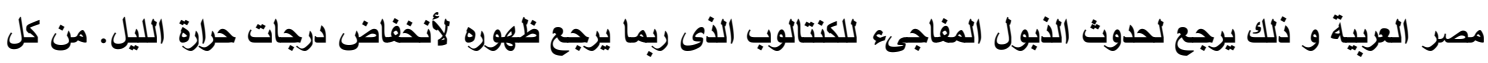

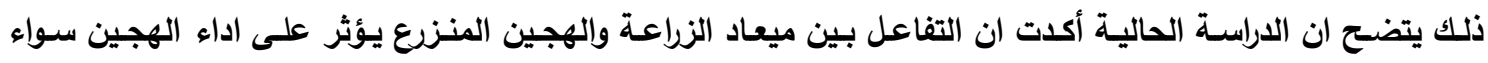
بالإيجاب أو السلب طبقاً للتفاعل بين الطراز الوراثى والظروف البئية.

أسماء السادة المحكمين

معهد بحوث البساتين - مركز البحوث الزراعية - الجيزة أ.د/ سيد محمـود أحمد العدين

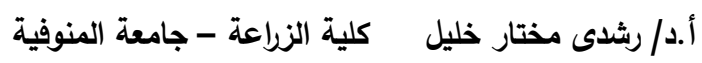


